Review

\title{
Fabrication Methods and Luminescent Properties of ZnO Materials for Light-Emitting Diodes
}

\section{Ching-Ting Lee}

Institute of Microelectronics, Department of Electrical Engineering, National Cheng Kung University, Tainan 701, Taiwan; E-Mail: ctlee@ee.ncku.edu.tw; Tel.: 886-6-2082368; Fax: 886-6-2082368

Received: 15 January 2010; in revised form: 8 February 2010 / Accepted: 19 March 2010 /

Published: 24 March 2010

\begin{abstract}
Zinc oxide $(\mathrm{ZnO})$ is a potential candidate material for optoelectronic applications, especially for blue to ultraviolet light emitting devices, due to its fundamental advantages, such as direct wide band gap of $3.37 \mathrm{eV}$, large exciton binding energy of $60 \mathrm{meV}$, and high optical gain of $320 \mathrm{~cm}^{-1}$ at room temperature. Its luminescent properties have been intensively investigated for samples, in the form of bulk, thin film, or nanostructure, prepared by various methods and doped with different impurities. In this paper, we first review briefly the recent progress in this field. Then a comprehensive summary of the research carried out in our laboratory on $\mathrm{ZnO}$ preparation and its luminescent properties, will be presented, in which the involved samples include $\mathrm{ZnO}$ films and nanorods prepared with different methods and doped with n-type or p-type impurities. The results of $\mathrm{ZnO}$ based LEDs will also be discussed.
\end{abstract}

Keywords: $\mathrm{ZnO}$ thin film; fabrication methods; luminescent properties; defect states; conductive types; nanostructured $\mathrm{ZnO}$; light-emitting diodes

\section{Introduction}

Zinc oxide $(\mathrm{ZnO})$ based materials are potential candidates for optoelectronic applications, especially for blue to ultraviolet light emitting devices, due to its fundamental advantages, such as direct wide band gap $3.37 \mathrm{eV}$, large exciton binding energy $60 \mathrm{meV}$, and high optical gain $320 \mathrm{~cm}^{-1}$ at room temperature. Intensive research efforts have focused on $\mathrm{ZnO}$ and related devices for many decades. The quality of $\mathrm{ZnO}$ in the forms of both bulk and thin film has been improved substantially. The nanostructured $\mathrm{ZnO}$ materials have attracted great attention and various dimensions and shapes have been prepared. On the other hand, the luminescent properties of the $\mathrm{ZnO}$ related materials have 
been extensively investigated. The $\mathrm{ZnO}$ based LEDs of various device structures have been demonstrated. In addition, the exploration of new preparation methods is still in progress.

In terms of the $\mathrm{ZnO}$ related investigations, we can say that great progress has been achieved, but there are still some obstacles to be overcome for realizing its wide optoelectronic applications, which remains a hot research direction. Large numbers of researchers are steadily working to explore this potential and promising field, and thousands of research papers are published each year. It is noted that various aspects of the investigation have been reviewed, such as in the comprehensive review papers $[1,2]$. In this paper, instead of a comprehensive review, we will emphasize the recent progress in a few selected topics we are interested in. For each topic, recent progress will be briefly reviewed and then the research activity conducted in our lab will be introduced in detail.

This paper is arranged as follows. Section 2 is devoted to the progress in $\mathrm{ZnO}$ material preparation methods, especially the vapor cooling condensation method newly developed in our lab. Section 3 comments on the recent progress in the investigation on the luminescence of native defects, a widely observed phenomenon in various $\mathrm{ZnO}$ materials. The theoretical study of unintentional n-type conductivity is reviewed in Section 4. The exploration on p-type $\mathrm{ZnO}$ carried out in our lab is introduced in Section 5. The research of nanostructured $\mathrm{ZnO}$ materials, both on their preparation and properties, are summarized in Section 6. In Section 7, after a brief review, the recent progress in the research of $\mathrm{ZnO}$ based light emitting diodes conducted in our laboratory is presented, followed by a short summary in Section 8.

\section{Preparation Methods of ZnO Films}

Growth of bulk $\mathrm{ZnO}$ crystals is mainly carried out by hydrothermal [3-6], vapor-phase [7-9], and melt growth $[10,11]$ methods. However, the deposition of $\mathrm{ZnO}$ thin films has attracted more attention due to its application in optoelectronics and sensor devices. Many different techniques such as sputtering (dc sputtering, rf sputtering, and reactive sputtering) [12-20], pulsed laser deposition (PLD) [21,22], molecular beam epitaxy (MBE) [23-26], chemical vapor deposition (CVD) (including metal organic chemical vapor deposition ) [27-31], aqueous solution growth [32], spray pyrolysis [3,34], sol-gel method [35-38] and vapor cooling condensation method [39] have been used in the preparation of $\mathrm{ZnO}$ thin films as well as nanostructured $\mathrm{ZnO}$.

$\mathrm{Rf}$ sputtering is one of the most popular growth techniques for $\mathrm{ZnO}$ thin films. Although the earlier sputtered materials were polycrystalline or even amorphous, some research [16] has reported the high-quality single-crystal $\mathrm{ZnO}$ films deposited on sapphire (0001) by rf magnetron sputtering. They found that a high substrate temperature was essential to improve the crystal structure, but rf power had to be adjusted for the appropriate growth rate. We have extensively investigated the relationship between the crystal structure, doping concentration and properties of the sputtered films and the sputtering conditions [18-20]. Figure 1 shows a schematic of the rf magnetron co-sputtering system used in our lab. In this system [40], a dual rf power supply with synchronized phase is employed to control the rf power at the $\mathrm{ZnO}$ target and the dopant target, respectively. The substrate holder is rotating during the deposition to improve the uniformity of the thickness and the doping content of the deposited films. The substrate holder temperature can be controlled too. 
Figure 1. Schematic diagram of the co-sputtering system.

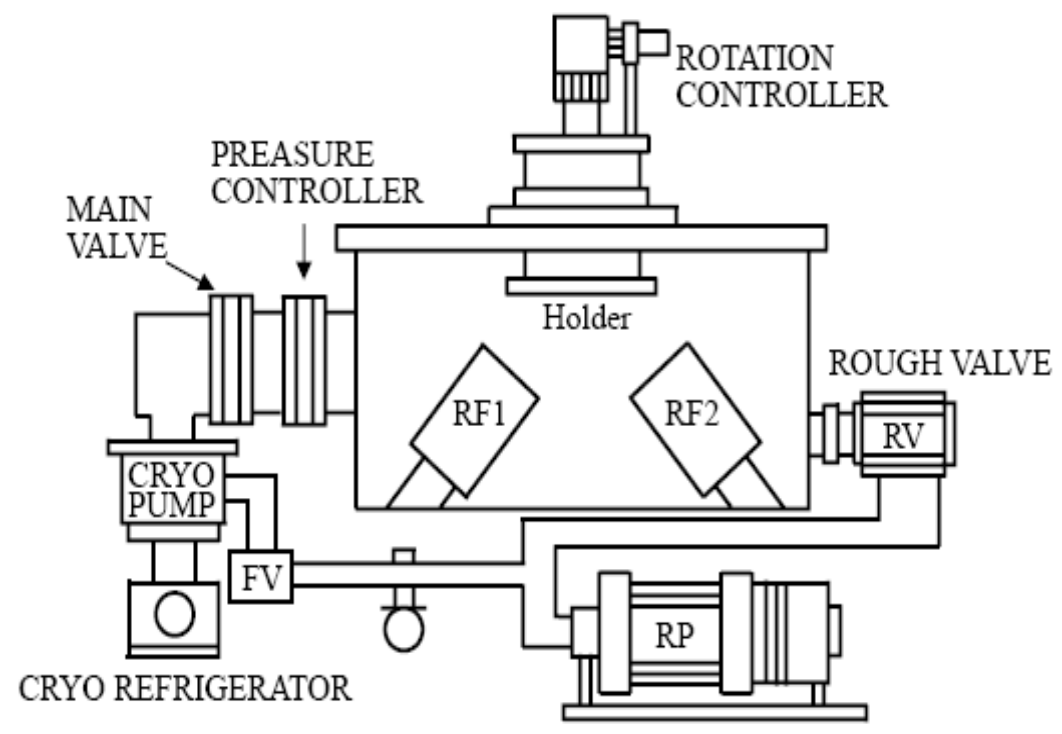

Figure 2 shows the FE-SEM images of (a) undoped $\mathrm{ZnO}$ film and co-sputtered $\mathrm{Al}-\mathrm{ZnO}$ films, with the rf power on $\mathrm{ZnO}$ target fixed and the power supplied to Al target to be (b) $26 \mathrm{~W}$, (c) $40 \mathrm{~W}$, and (d) $55 \mathrm{~W}$ [18]. In these conditions the corresponding theoretical $\mathrm{Al}$ atomic ratios $[\mathrm{Al} /(\mathrm{Al}+\mathrm{Zn})$ at \%] in the co-sputtered $\mathrm{ZnO}$ films were evaluated to be (b) 7.5, (c) 10, and (d) 12.5 at \% according to the individual deposition rates of the undoped $\mathrm{ZnO}$ and metallic $\mathrm{Al}$ films. All the SEM images show a grainy morphology. It was found that the grain size decreased as the $\mathrm{Al}$ atomic ratio in the co-sputtered film increased, indicating that the grain growth was inhibited by introducing $\mathrm{Al}$ into the $\mathrm{ZnO}$ matrix. The inhomogeneous wedge-like grains showed an evidence of lateral growth that resulted in the random growth orientation. The evolutions of the grain size and shape observed by FE-SEM coincided with the results derived from the XRD diffraction patterns.

The effects of working pressures on the electronic and optical properties of undoped $\mathrm{ZnO}$ films deposited on Si substrates were studied [19]. It is found that the resistivity of the deposited $\mathrm{ZnO}$ films decreases with the working pressure, and the resistivity of $4.3 \times 10^{-3} \Omega \mathrm{cm}$ can be obtained without post annealing (Table 1). The optical transmittance measurements gave a value above $90 \%$ at a wavelength longer than $430 \mathrm{~nm}$ and about $80 \%$ at the wavelength of $380 \mathrm{~nm}$ for the deposited film. The time-resolved PL measurement showed that the carrier lifetime increases with the working pressure, indicating a reduction of nonradiative recombination rate. It can be attributed to the decrease of oxygen vacancies in the $\mathrm{ZnO}$ films deposited at a higher working pressure. This result is verified by the photoluminescence measurements (Figure 3), in which the UV PL intensity increases with the working pressure. Besides, with increasing the working pressure, the absorption coefficient decreased and the associated optical energy gap of $\mathrm{ZnO}$ thin films increased. The contents of sputtering gas are also important for the deposition, which will be discussed later. 
Figure 2. FE-SEM images of the (a) undoped $\mathrm{ZnO}$ and co-sputtered $\mathrm{Al}-\mathrm{ZnO}$ films at theoretical Al atomic ratios of (b) 7.5, (c) 10, and (d) 12.5 at. \%. Reprinted from [18] with permission.
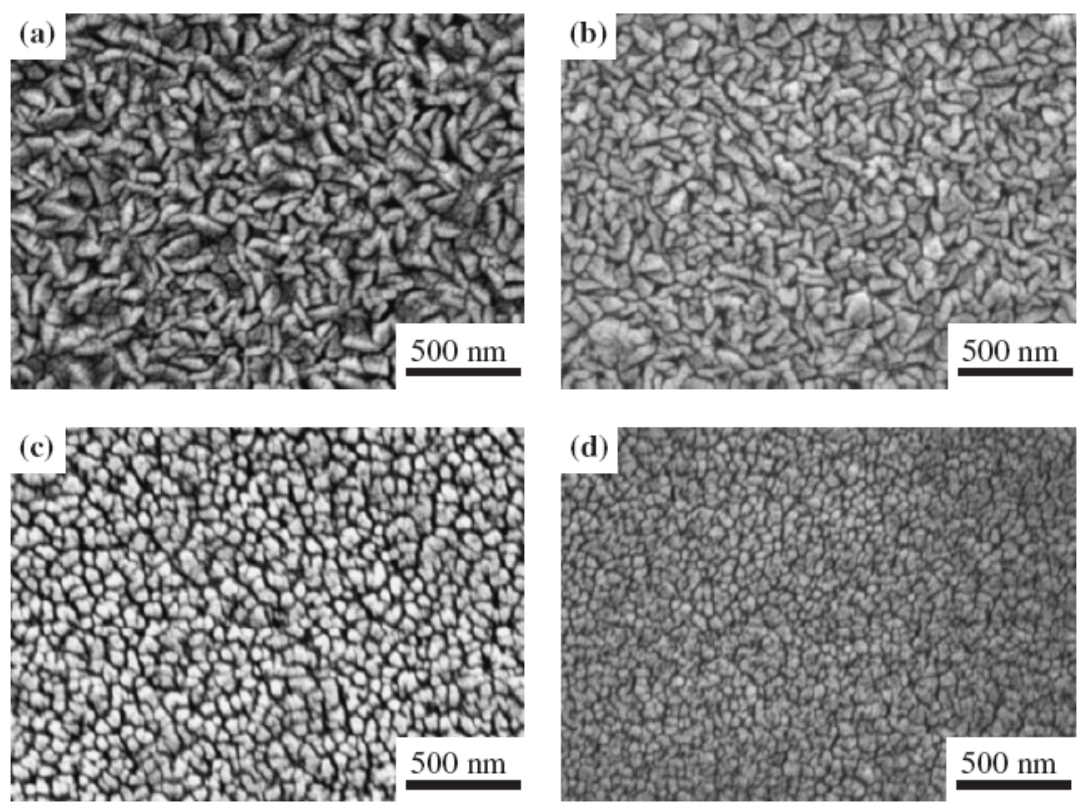

Table 1. Resistivity, electron mobility, electron concentration and deposition rate of $\mathrm{ZnO}$ films deposited on Si substrates at 100W rf power and $20 \mathrm{sccm}$ Ar flow rate with various working pressures. Reprinted from [19] with permission.

Working pressure Property

(mTorr)

Resistivity Electron mobility Electron concentration Deposition rate Sample no.

\begin{tabular}{lccccc} 
& $\left(\times 10^{-3} \Omega \mathrm{cm}\right)$ & $\left(\mathrm{cm}^{2} \mathrm{~V}^{-1} \mathrm{~s}^{-1}\right)$ & $\left(1 \mathrm{~cm}^{-3}\right)$ & $\left(\mathrm{nm} \mathrm{min}^{-1}\right)$ \\
\hline 100 & 44 & 1.75 & $8.04 \times 10^{19}$ & 5.33 & (a) \\
150 & 24 & 2.83 & $9.19 \times 10^{19}$ & 3.96 & (b) \\
200 & 8.9 & 6.33 & $1.10 \times 10^{20}$ & 3.33 & (c) \\
250 & 4.3 & 10.1 & $1.42 \times 10^{20}$ & 3.10 & (d) \\
\hline
\end{tabular}

Figure 3. Photoluminescence spectra of $\mathrm{ZnO}$ films deposited under various working pressures. Reprinted from [19] with permission.

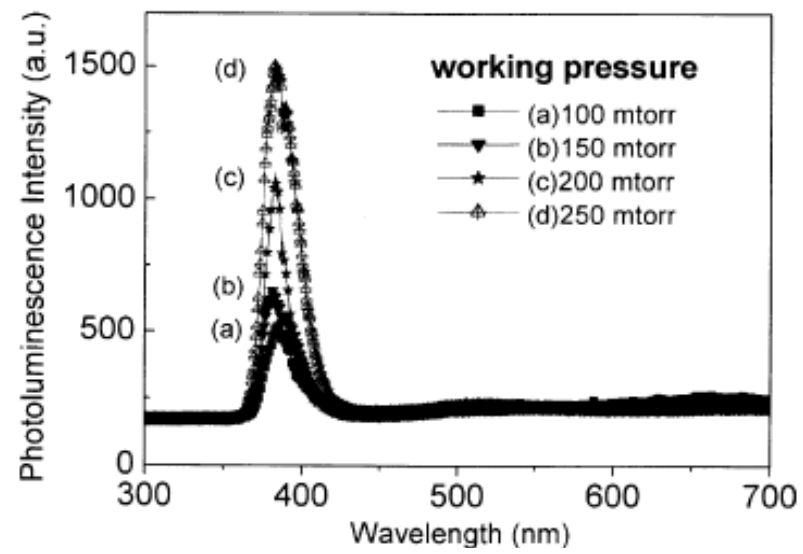


Figure 4 shows the XRD patterns of undoped $\mathrm{ZnO}$ and $\mathrm{AlN}$ codoped $\mathrm{ZnO}$ films, showing the effect of post-annealing [20]. An apparent diffraction peak of $\mathrm{ZnO}$ (002) phase was observed in the diffraction pattern of as-deposited undoped $\mathrm{ZnO}$ film, while the crystalline structure of as-deposited AlN codoped $\mathrm{ZnO}$ film was more disordered, as seen from Figure 4(a). However both the codoped and undoped $\mathrm{ZnO}$ films annealed at $400{ }^{\circ} \mathrm{C}$ under nitrogen ambient exhibited polycrystalline structures with the dominated diffraction peaks of $\mathrm{ZnO}(002)$ and (101) phases in the diffraction patterns. In addition, except for the $\mathrm{ZnO}$-related diffraction peaks, a weak diffraction peak determined as $\mathrm{Zn}_{3} \mathrm{~N}_{2}$ (222) was observed from the annealed Al-N codoped $\mathrm{ZnO}$ film diffraction pattern. The appearance of the zinc nitride phase was believed to be the nitrification reaction of the excess $\mathrm{Zn}$ and $\mathrm{N}$ atoms in the codoped films, indicating the excitation of the $\mathrm{N}$ ions after thermal annealing. $P$-type conductive behavior of $\mathrm{AlN}$ codoped $\mathrm{ZnO}$ was obtained after an additive post-annealing treatment at temperatures ranging from $400-600{ }^{\circ} \mathrm{C}$ under nitrogen ambient for $30 \mathrm{~min}$, which will be discussed in Section 5 .

Figure 4. XPD patterns of undoped $\mathrm{ZnO}$ film and $\mathrm{AlN}$ codoped $\mathrm{ZnO}$ film (theoretical $\mathrm{Al}$ atomic ratio of $10 \%$ ). (a) as-deposited (b) post-annealed at $400{ }^{\circ} \mathrm{C}$ under nitrogen ambient for $30 \mathrm{~min}$. Reprinted from Ref. [20] with permission.
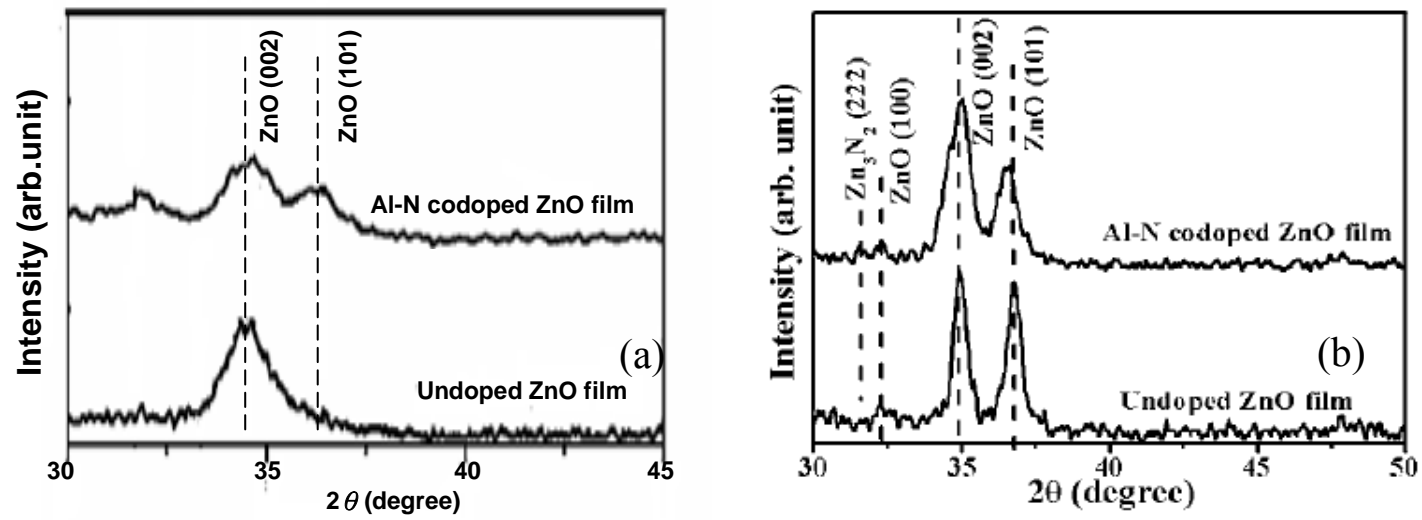

We have developed a vapor cooling condensation method [39], with which high quality intrinsic $\mathrm{ZnO}$ (i-ZnO) films can be fabricated at low temperature. The schematic vapor cooling condensation system is shown in Figure 5.

Figure 5. Setup of vapor cooling evaporation system.

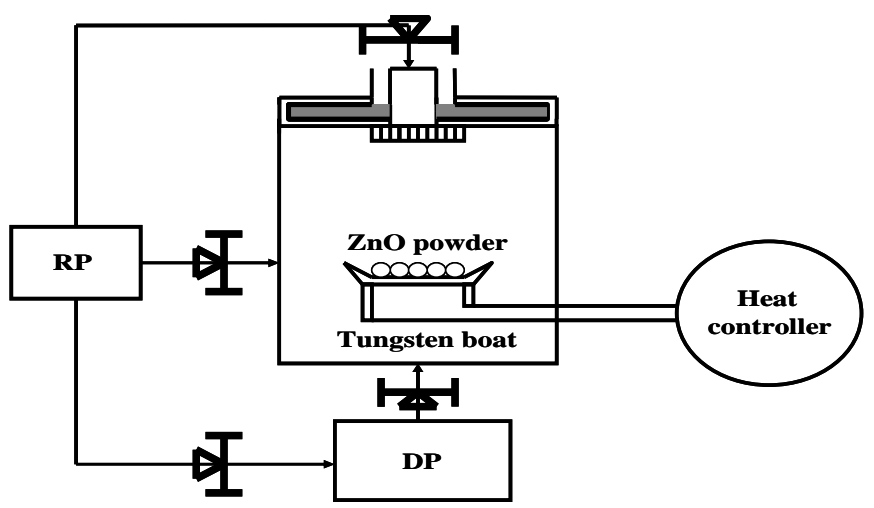


By heating the tungsten boat loaded with $0.85 \mathrm{~g}$ of $\mathrm{ZnO}$ powder, a $300 \mathrm{~nm}$ thick $i$ - $\mathrm{ZnO}$ film was deposited on the substrate cooled by liquid nitrogen. An electron concentration of $7.6 \times 10^{15} \mathrm{~cm}^{-3}$ and mobility of $2.1 \mathrm{~cm}^{2} / \mathrm{Vs}$ of the deposited $i-\mathrm{ZnO}$ film at room temperature were obtained. The room temperature PL spectrum of the resultant $i-\mathrm{ZnO}$ film is shown in Figure 6, which consists of a strong ultraviolet emission band centering at $382 \mathrm{~nm}$ with a full width at half maximum of $13 \mathrm{~nm}$. The absence of visible emission implies a very low defect concentration owing to the low temperature growth. The system was also used for $n-\mathrm{ZnO}$ films deposition with pure $\mathrm{ZnO}$ and $\mathrm{In}$ as source materials. The electron concentration and mobility of the deposited $\mathrm{ZnO}$ :In films were $1.7 \times 10^{20} \mathrm{~cm}^{-3}$ and $3.7 \mathrm{~cm}^{2} / \mathrm{Vs}$, respectively. The PL spectrum of the $n-\mathrm{ZnO}$ :In films is also presented in Figure 6.

Figure 6. Room temperature PL spectra of the $i-\mathrm{ZnO}$ and $n-\mathrm{ZnO}: \mathrm{In}$ films, excited at $325 \mathrm{~nm}$. Reprinted from Ref. [39] with permission.

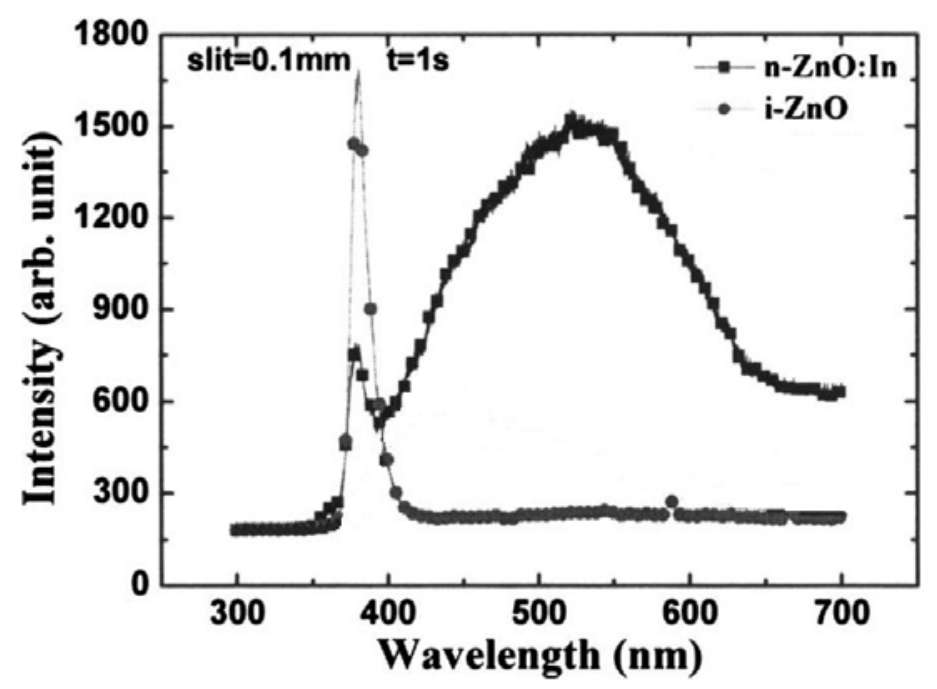

In order to realize modern devices, modulation of the bandgap of the material is required, which has been demonstrated by the development of $\mathrm{Zn}_{1-\mathrm{x}} \mathrm{Mg}_{\mathrm{x}} \mathrm{O}$ [26,41-43] and $\mathrm{Zn}_{1-\mathrm{z}} \mathrm{Be}_{\mathrm{z}} \mathrm{O}$ [44,45] alloys for the larger bandgap material and $\mathrm{Zn}_{1-y} \mathrm{Cd}_{\mathrm{y}} \mathrm{O}$ alloy for the smaller bandgap material $[46,47]$, showing a wide tuning range for $\mathrm{ZnO}$-based materials. In our lab sol-gel method was used to perform the band gap engineering [37,38]. $\mathrm{Zn}_{1-x} \mathrm{Mg}_{x} \mathrm{O}(\mathrm{x}=0.027,0.042$, and 0.060) films were prepared by the sol-gel method and spin coating technique, using $\mathrm{Zn}\left(\mathrm{CH}_{3} \mathrm{COO}\right)_{2} \cdot \mathrm{H}_{2} \mathrm{O}$ and $\mathrm{Mg}\left(\mathrm{CH}_{3} \mathrm{COO}\right)_{2} \cdot \mathrm{H}_{2} \mathrm{O}$ as start materials and methanol as solvent. After depositing by spin coating, the films were dried at $300{ }^{\circ} \mathrm{C}$ for $10 \mathrm{~min}$ on a hotplate to evaporate the solvent and remove organic residuals. The procedures from coating to drying were repeated many times. The films were finally annealed in air at $500^{\circ} \mathrm{C}$ for $4 \mathrm{~h}$. XRD profiles of the resultant $\mathrm{Zn}_{1-x} \mathrm{Mg}_{x} \mathrm{O}$ films suggest the formation of wurtzite structure with a preferred $c$-axis orientation. And no evidence of $\mathrm{MgO}$ phase was seen, confirming the monophasic nature of these compositions. Figure 7 is the BEL (Band-edge luminescence) spectra of $\mathrm{Zn}_{1-x} \mathrm{Mg}_{x} \mathrm{O}$ ( $x=0.027,0.042$ and 0.060) films [38]. Obvious blue shift was observed when the content of $\mathrm{Mg}$ increased, which resulted from an increasing of the band gap. 
Figure 7. BEL spectra of the $\mathrm{Zn}_{1-x} \mathrm{Mg}_{x} \mathrm{O}(x=0.027,0.042$ and 0.060$)$ films in the region from 3.2-3.9 eV. Reprinted from Ref. [38] with permission.



\section{Photoluminescence (PL) of Native Defects in ZnO}

The origin of luminescent transitions is always one of central investigation topics for luminescent materials. Large amount of research efforts have been devoted to the luminescence properties of $\mathrm{ZnO}$ for more than half a century, including both intrinsic and extrinsic luminescence. However, in comparison with the study on the extrinsic luminescence of $\mathrm{ZnO}$, the exact origin of its intrinsic luminescence due to native defects is still controversial. In this section, we will review the new progress obtained in recent years on the luminescence of native defects in $\mathrm{ZnO}$, especially the progress in theoretical study of the defect states.

A typical low-temperature PL spectrum of the nominally undoped $\mathrm{ZnO}$ contains sharp and intense excitonic lines in the UV region of the optical spectrum, with one or more broad bands in the visible region. In spite of numerous reports on red, orange, yellow, and green broad bands, observed mostly at room temperature, their likely geneses are still speculative at this time. These bands are attributed to a variety of native defects such as oxygen vacancies $V_{O}$, zinc vacancies $V_{Z n}$, and oxygen interstitials $O_{i}$, but very little is known about the properties of defects that cause various bands in the luminescence of undoped $\mathrm{ZnO}$.

For example, the well-known green luminescence (GL) band centering at about $2.5 \mathrm{eV}$ in undoped $\mathrm{ZnO}$ usually dominates the defect-related part of the PL spectrum. However, the nature of it remained controversial for decades. Özgür et al. [1] pointed out that while similar in position and width, these PL bands may actually be of different origins: the GL band with a characteristic fine structure is most likely related to the copper impurities [48], whereas the structureless GL band with nearly the same position and width may be related to native point defects such as $V_{O}$ or $V_{Z n}$. Meanwhile, some works [49-52] speculated the oxygen vacancies, some works [53,54] speculated the zinc vacancies cause the GL band.

Especially Leiter et al. [55,56] have identified $V_{O}$ as the defect responsible for the structureless GL band in $\mathrm{ZnO}$ and demonstrated striking similarities of this defect to the anion vacancy in other ionic host crystals: $\mathrm{BaO}, \mathrm{SrO}, \mathrm{CaO}$, and $\mathrm{MgO}$ (F centers). In their model the two-electron ground state of the neutral $V_{O}$ is a diamagnetic singlet state, absorption of a photon transforms the system into a singlet 
excited state, followed by a nonradiative relaxation into the emissive, paramagnetic state $(S=1)$ which can be detected by ODMR, then the optical cycle is closed by radiative recombination back to the $\mathrm{S}=0$ ground state. In a recent work [57], Hofmann et al. concluded that the PL and DLTS (deep level transient spectroscopy) experimental results suggested a correlation between the GL and a donor level $530 \mathrm{meV}$ below the conduction band, which is attributed to the $V_{O}^{0 /++}$ transition of oxygen vacancies.

The GL bands were often found in observed PL spectra of samples prepared in our lab and they usually were attributed to oxygen vacancy defects. For example, a green-band emission was observed both for the undoped $\mathrm{ZnO}$ film and the p-type AlN codoped $\mathrm{ZnO}$ films [58], and the intensities were smaller for the latter, which implies that less oxygen vacancies existed in them. However, in a work on $\mathrm{ZnO}-\mathrm{on}-\mathrm{GaN}$ heterostructures grown using the vapor cooling condensation system [39], compared to undoped $\mathrm{ZnO}$, a remarkable broad green emission band in $\mathrm{ZnO}$ :In films was observed, and it was considered to be induced by the oxygen vacancies. Moreover, in our work on ultraviolet (UV) emission of In-doped $\mathrm{ZnO}$ nanodisks grown by carbothermal reduction at $1000{ }^{\circ} \mathrm{C}$ [59], air-cooled $\mathrm{ZnO}$ nanodisks showed a strong green emission, while furnace cooling in conjunction with introducing $\mathrm{O}_{2}$, around $1.0 \%$, into flowing Ar during the growth significantly enhanced the growth rate and UV emission of $\mathrm{ZnO}$ nanodisks (while the green emission was significantly suppressed). The causes were attributed to the reduction of oxygen vacancies and surface defects. Besides, for the $\mathrm{Zn}_{1-x} \mathrm{Mg}_{x} \mathrm{O}$ films prepared by the sol-gel technique [38], a GL was observed and its intensity decreased (while the intensity of the band-edge luminescence was seen to increase) with the increase of $\mathrm{Mg}$ content, which was partly attributed to a decrease in the number of $V_{O}$-related defects.

However, deferent results were also reported. Recently Kappers et al. [60] studied ZnO crystals grown by the seeded chemical vapor transport method. The samples were irradiated at room temperature with $1.5 \mathrm{MeV}$ electrons to create oxygen and zinc vacancies, and then characterized using optical absorption, PL, and electron paramagnetic resonance (EPR). It was found that no correlation existed between the green emission and the presence of oxygen and/or zinc vacancies. Similarly, Vlasenko and Watkins [61] also found that electron irradiation produced $\mathrm{O}$ vacancies and other defects in $\mathrm{ZnO}$, leading to a reduction in GL and an increase in PL bands near 600 and $700 \mathrm{~nm}$. These works questioned the assumption that GL is related to $V_{O}$. In addition, we noticed that the formation energy of zinc vacancies is as high as $4 \mathrm{eV}$ in n-type $\mathrm{ZnO}$ [62], which implies that the concentration of $V_{Z n}$ in $\mathrm{ZnO}$ would be too low to cause the observed green band in the PL spectrum. So are the other native defects, for example, zinc interstitials [63] and oxide antisite defects [64,65], as have been suggested previously.

Recently, Reshchikov et al. [66] systematically investigated the PL of defects in ZnO. They analyzed carefully the PL spectra obtained in wide ranges of excitation power densities and sample temperatures, as well as the spectra at various time delays after a pulsed excitation. They resolved a number of PL bands in the visible region of the PL spectrum, as seen in Figure 8 and Table 2 (some bands could not be observed at either 10 or $300 \mathrm{~K}$ ) in which $\mathrm{E}_{\mathrm{A}}$ is the activation energy, Tcr is the critical temperature above which the quenching begins, both are quantities describing quenching behavior of the PL band. 
Figure 8. Selected PL bands observed at $10 \mathrm{~K}$ in $\mathrm{ZnO}$. Intensity is normalized at band maxima. Reprinted from Ref. [66] with permission.

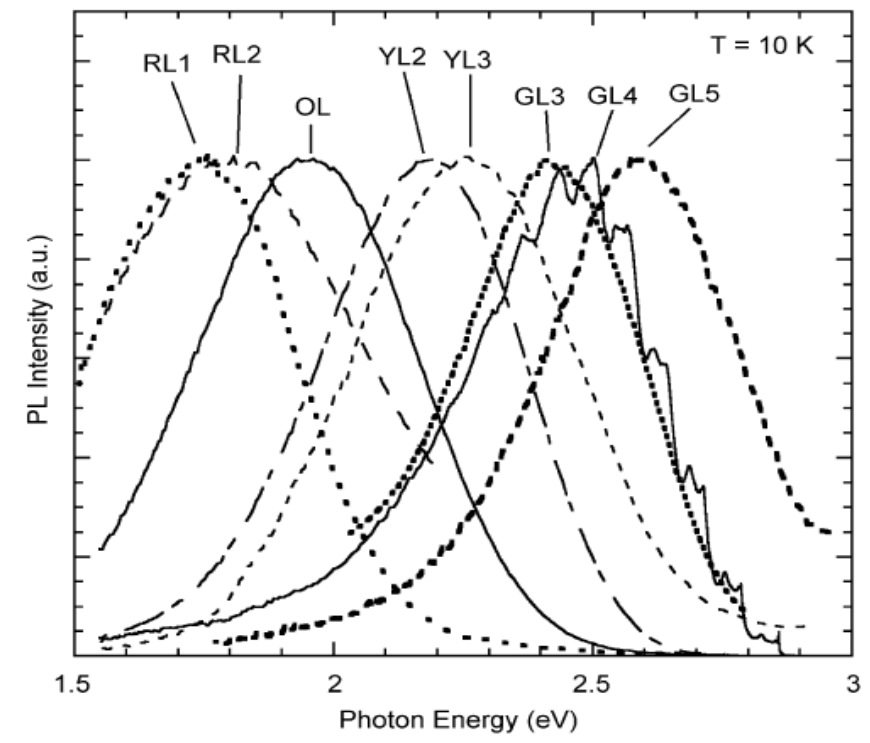

Table 2. Main characteristics of visible PL bands in $\mathrm{ZnO}$. Reprinted from Ref. [66] with permission.

\begin{tabular}{lllrr}
\hline PL band & \multicolumn{2}{l}{ Peak position $(\mathrm{eV})$} & $\mathrm{E}_{\mathrm{A}}(\mathrm{meV})$ & $\mathrm{T}_{\mathrm{cr}}(\mathrm{K})$ \\
\cline { 2 - 3 } & $10 \mathrm{~K}$ & $300 \mathrm{~K}$ & & \\
\hline RL1 & 1.75 & $\sim 1.75$ & 15 & 30 \\
RL2 & 1.8 & $\sim 1.9$ & $\sim 150$ & 200 \\
OL & 1.95 & 2.12 & 500 & 240 \\
YL1 & 2.15 & - & 450 & 240 \\
YL2 & 2.19 & 2.2 & 85 & 100 \\
YL3 & 2.25 & - & 500 & 200 \\
GL1 & - & $\sim 2.3$ & $\sim 500$ & 260 \\
GL2 & 2.38 & - & 35 & 40 \\
GL3 & 2.42 & 2.44 & 400 & 260 \\
GL4(Cu) & 2.47 & 2.47 & $\sim 80$ & 50 \\
GL5 & 2.6 & - & 120 & 100 \\
\hline
\end{tabular}

Based on the careful analyses of the spectra they reached the following conclusion. The majority of the defects remained unidentified and transitions responsible for particular bands need to be verified. The most recognizable PL bands are the OL band peaking at $1.96 \mathrm{eV}$ at $10 \mathrm{~K}$ (assigned to transitions from shallow donors to a deep acceptor level about $0.5-0.6 \mathrm{eV}$ above the valence band [67]) and the $\mathrm{Cu}$-related GL4 band with the characteristic fine structure.

Theoretically, there were also some first-principles calculations on electronic structure of defects in $\mathrm{ZnO}[68,69]$ based mainly on the local density functional approximation (LDA) or added with various corrections $(\mathrm{LDA}+U, \mathrm{LDA} / \mathrm{GGA}$, etc.). However, these works always gave the fundamental band gap value $\mathrm{E}_{\mathrm{g}}<1 \mathrm{eV}$ (compared to experiment value $3.4 \mathrm{eV}$ ) for several tens of years, therefore the defect levels within the gap can only be estimated by means of various empirical correction. Recently, based on the hybrid density functional computation program, a few authors $[62,70,71]$ have made ab initio 
calculation of the band gap, atomic and electronic structure (especially of the defects) for ZnO. Their work gave correct band gap $\left(\mathrm{E}_{\mathrm{g}}=3.4 \mathrm{eV}\right)$, and so the calculated results for defect states and levels within the band gap are much more reliable.

To understand PL related native defect states in $\mathrm{ZnO}, \mathrm{Hu}$ and $\mathrm{Pan}$ [71] studied vacancies $V_{O}^{q}, V_{Z n}^{q}$, and self-interstitials $Z n_{i, 0}^{q}, O_{i, \mathrm{o}}^{q}$ (occupying octahedral sites) with $\mathrm{q}=0,+1$ or $-1,+2$ or -2 . As part of the results, their table 1 listed all the calculated single-electronic energy levels (Kohn-Sham levels) at the Gama point of the Brillouin zone within the band gap of a modeling defect-crystal (MDC). In the calculation, they used a 72-atom supercell containing one isolated native defect of above kinds and the atom-configuration was completely relaxed. Their calculation is spin-polarized, namely, the same orbital state with spin-up or spin-down has different energy generally. This is obvious for supercell of odd-number electrons, in which the number of spin-up electrons must be different from the number of spin-down electrons, like the one containing defect with $\mathrm{q}=+1$ or -1 , since the exchange potential in Kohn-Sham equation is different for -up or -down single electron. However, for the $V_{Z n}^{0}$-containing MDC here, the calculated result is also spin-polarized. As pointed out by C.H. Patterson [70], the neutral Zn vacancy contains two "dangling holes". It is noted that the hole-orbitals (unoccupied electron-orbitals) mainly consist of $2 p$ orbitals of the four oxygen atoms around the vacancy. The "total-energy minimization" produces a spin-split single-electron energy level scheme where spin-up levels descend and are totally occupied and only two high-energy spin-down orbitals are left to be empty. Usually each MDC has several defect-states, the number of defect-levels within the band gap and the total number of electrons occupying each level can be different from each other. Therefore, the positions of the Fermi levels and the level-occupation under temperature $\mathrm{T}=0$ are also different for different MDC.

For the reader's convenience, in Figure 9 we plot an energy level diagram based on the data in Table 1 of their paper [71].

Figure 9. Calculated energy levels of native defects in the band gap of $\mathrm{ZnO}$. Based on table 1 of Ref. [71].

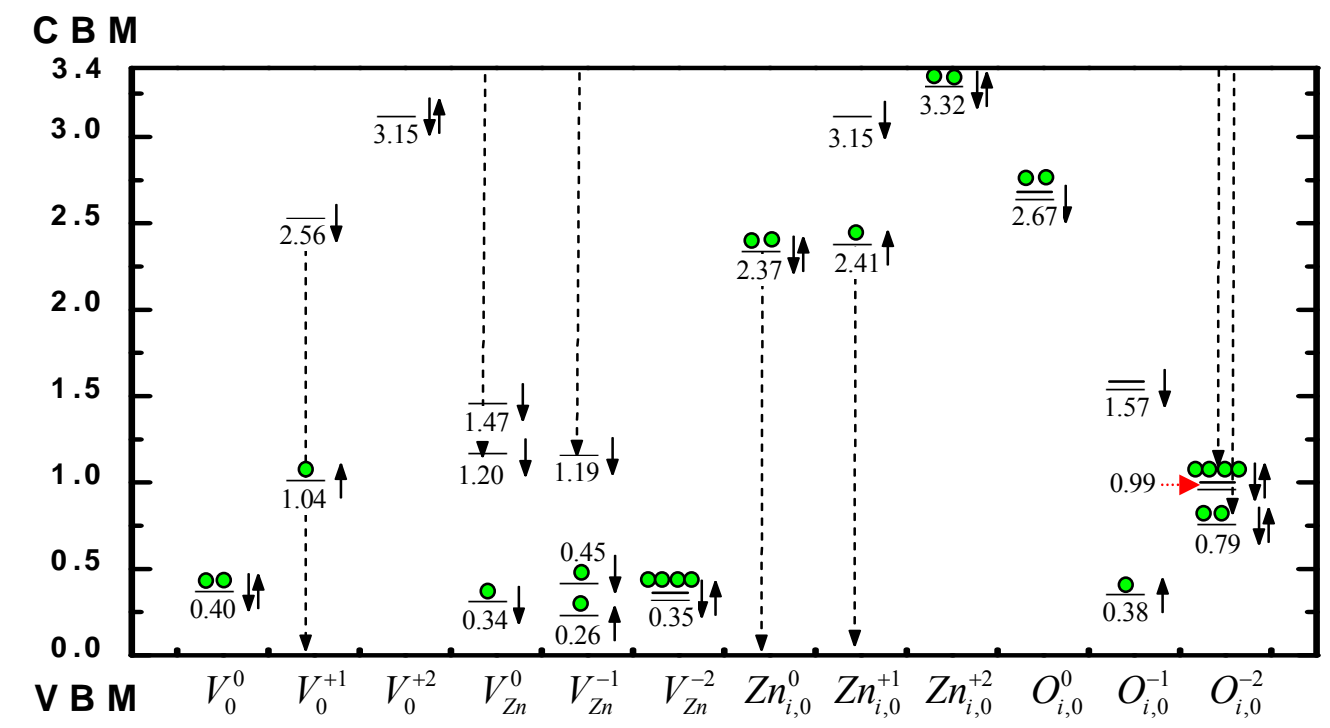




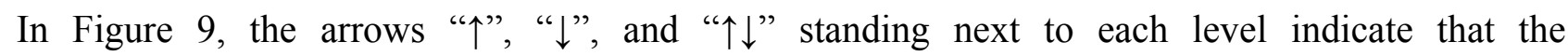
corresponding levels are "spin up", "spin down", and "spin degeneration", respectively. The double line " $=$ " represents the doubly degenerate orbital. The solid sphere "•" represents an electron that occupies the level beneath it. The figure represents the occupation scheme under the temperature $\mathrm{T}=0$ for the ground state of the studied system containing the defect presented explicitly at the bottom of the figure. The dashed vertical arrow lines show the possible transitions corresponding to the green luminescence. The transitions conduction-band minimum $(\mathrm{CBM}) \rightarrow 1.47 \mathrm{eV}\left(V_{Z n}^{0}\right)$ and $\mathrm{CBM} \rightarrow 1.57 \mathrm{eV}$ $\left(O_{i, o}^{-1}\right)$ correspond probably to the orange and red luminescence, respectively.

If only the peak positions of the PL bands are concerned, by comparing Table 2 with the figure shown above, we can make the following assignment:

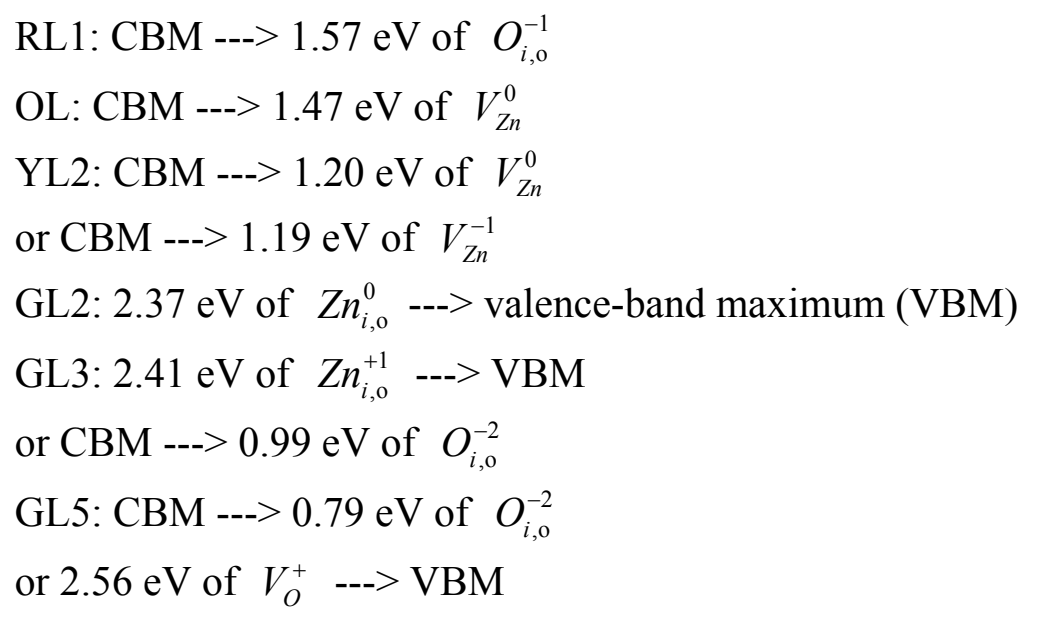

From the calculated results, they derived the conclusion that both the vacancies and interstitials of $\mathrm{O}$ and $\mathrm{Zn}$ contribute to the green PL (2.2-2.6 eV) observed in various experiments.

It should be noted that the electron-phonon (or electron-lattice) interaction may be strong for localized electronic states of defects. That is, the relaxed atom-configurations of different charge states of a defect are, in general, different from each other. The defect $V_{O}$ in $\mathrm{ZnO}$ gives a typical example, for which the different charge states have very different relaxed atom-configurations. For the neutral defect $V_{O}^{0}$, the four $\mathrm{Zn}$ neighbors move inward, with the distances between these $\mathrm{Zn}$ atoms contracting by about $\Delta_{0}=-9 \%$ (or $-12 \%$ [72]) relative to that in perfect $\mathrm{ZnO}$, while for the charged $V_{O}^{2+}$, the distances expanding by about $\Delta_{2}=19 \%$ (or 23\% [72]). The origin of these large lattice relaxations can be interpreted by the change in electron distribution in different charge states of $V_{\mathrm{O}}$. The removal of an oxygen atom from the lattice breaks four bonds. The four "dangling bonds" on the surrounding $\mathrm{Zn}$ atoms combine to form a fully symmetric single-electron state $a_{1}$ of energy in the band gap (and three almost degenerate states located above the CBM). In the neutral charge state, the $a_{1}$ state is occupied by two electrons. The energy of the state is lowered as the four $\mathrm{Zn}$ atoms approach each other. At the same time, the $\mathrm{Zn}-\mathrm{O}$ bonds are stretched. Finally the gain in electronic energy balances the cost to stretch the $\mathrm{Zn}-\mathrm{O}$ bonds surrounding the vacancy at the corresponding equilibrium configuration, and the resulting $a_{1}$ state lies in the gap near the top of the valence band. In the $V_{O}^{+}$charge state, the $a_{1}$ state is occupied by one electron. In this case, the competition of the electronic energy with the strain energy results in the four $\mathrm{Zn}$ atoms displacing slightly outward $\left(\Delta_{1} \cong 2 \%\right)$, correspondingly the $a_{1}$ state moves towards the middle of the band gap. In the $V_{O}^{2+}$ configuration, the $a_{1}$ state is empty, 
which leads the four Zn atoms strongly relaxed outward, and the empty $a_{1}$ state lies near and below the conduction band edge.

Recently, refined results have been reported, in which Oba et al. [62] executed a first-principles calculation of the electronic structures of both charged and uncharged supercells containing 192 atoms by hybrid functional approach combining with careful finite-size corrections. The resultant band structures for perfect bulk $\mathrm{ZnO}$ and defect $\left(V_{O}^{0}, V_{O}^{2+}, \mathrm{Zn}_{i}^{0}\right)$ contained $\mathrm{ZnO}$ are presented in Figure 10.

Figure 10. Band structure for bulk $\mathrm{ZnO}$ and defects $V_{O}^{0}, V_{O}^{2+}, Z n_{i}^{0}$ contained ones, which was obtained using the hybrid functional. Shown below are the squared wave functions of the states designated by the arrows in the corresponding band diagram, which are plotted for the middle of the (0001) $\mathrm{Zn}$ and $\mathrm{O}$ planes adjacent to the defects. The projected $\mathrm{Zn}$ and $\mathrm{O}$ atom positions are denoted with green (dark) and yellow (light) circles, respectively. Reprinted from Ref. [62] with permission.

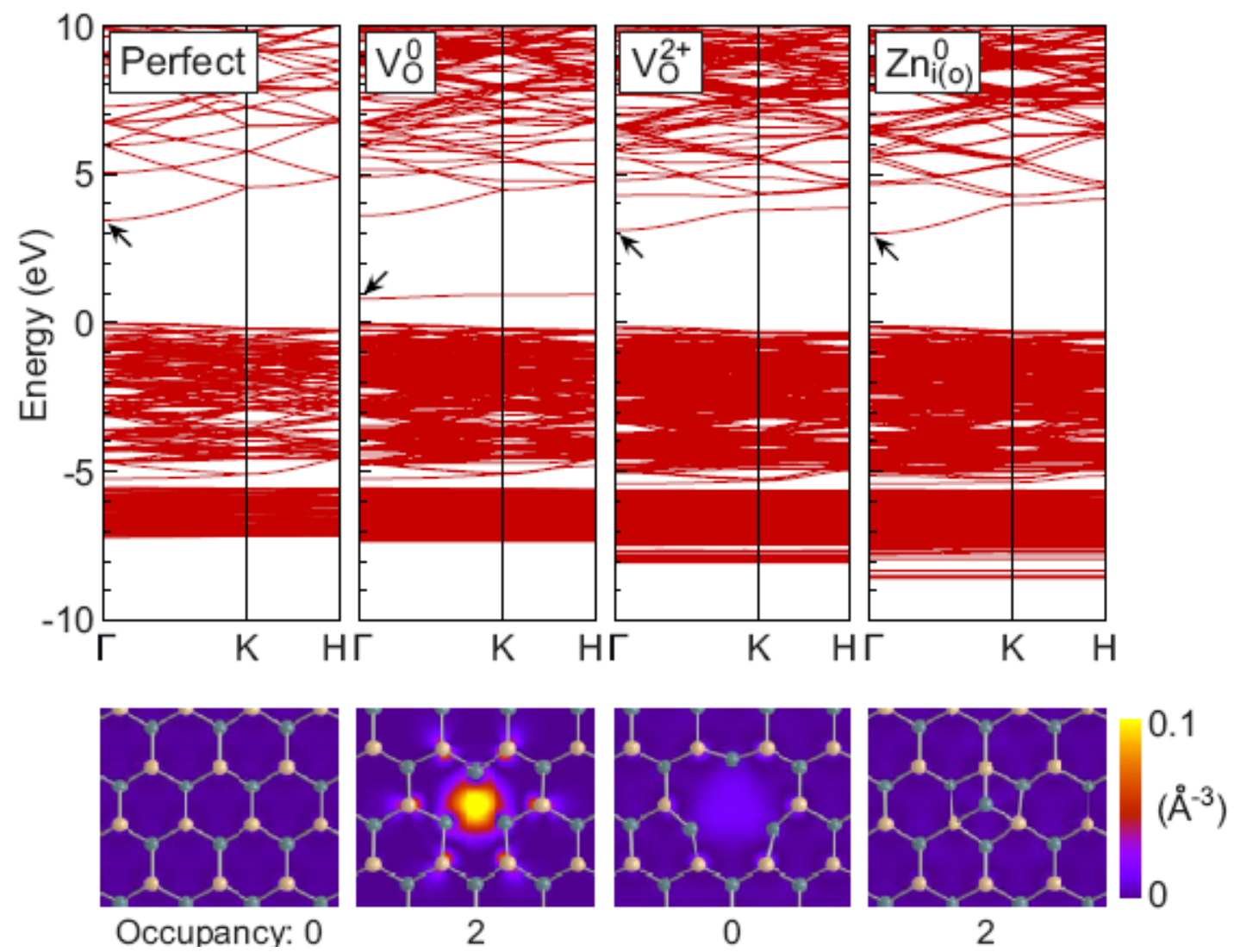

As for the relaxation of atomic configuration around defects, they found $\Delta_{0}=-10 \%$ and $\Delta_{2}=23 \%$ for $V_{O}$, not very different from the values given above. In their work, the calculation errors due to the spurious electrostatic interactions between defects in these finite-sized supercells were corrected by introducing the energy terms of $L^{-1}, L^{-3}, \ldots$ dependences (where $L$ is the average interdefect distance), among which the $L^{-1}$ term corresponds to the Madelung energy for an array of point charges $q_{c}$ in an effective medium. It is noteworthy that, based on their calculation results, in contrast to the localized nature of the defect $\left(V_{O}\right)$ states, the highest occupied state of $Z n_{i}^{0}$ is delocalized and comparable in energy position to the bottom of the conduction band of the perfect 
crystal. Due to this delocalized character, the removal of the electrons, i.e., changing the charge state to + or $2+$, does not alter the band structure. Furthermore, the filling of this delocalized conduction-band-like states does not effectively screen the charge of the point defect, leaving a long-range Madelung interaction (with $q_{c}=2$ ) between the point defects even in case of the neutral supercells. So does for the defects $Z n_{i}^{+}, Z n_{O}^{0}, Z n_{O}^{+}$(similarly for shallow impurity defects $H_{i}^{0}, H_{O}^{0}$, both of them have $q_{c}=1$ ).

However, it should be pointed out that the above calculation is based on a single electron approximation, in which even roughly from the point of view of Hartree approximation, the Kohn-Sham energy states are states of a single electron moving in an averaged field induced by interaction between electrons in a system. It is often to regard simply an optical transition as a transition of one electron between two Kohn-Sham levels of the system, calculating the difference between these levels as the transition energy. Actually, the optical transition energy of a multi-electron system is the difference of the total energies of the initial and final multi-electron states. The total energy of a multi-electron state contains the interaction between the electrons that occupy different single electron (Kohn-Sham) levels. Therefore the transition energy is generally different from the difference between the (transition-involved) two single electron energy levels within a single set of Kohn-Sham levels. In addition, different states of a multi-electronic system, in general, have different single-electron (Kohn-Sham) energy levels due to the different averaged field. In other words, the energies of all other electrons, and the interaction energy between them, are also changed after the studied one-electron optical transition, especially for transitions between different charge states of a localized multi-electron system as that in the case of defects. Then for properly describing the defect-related optical transition, a so-called optical transition level (see Section 4 for detail), an effective single electron energy level pertinent to the studied defect-related optical transition, has to be introduced into the band energy diagram instead of Kohn-Sham levels. Determination of the transition level is of great interest, but has not yet been systematically calculated as we know. Obviously the expected calculation will greatly push forward the study on the PL of defects in $\mathrm{ZnO}$.

\section{Theoretical Study of Unintentional N-Type Conductivity}

The electronic properties of $\mathrm{ZnO}$ were traditionally explained by invoking intrinsic defects - the native and unintentionally introduced point defects in the past decades of years. In particular, the frequently observed unintentional $n$-type conductivity was often attributed to oxygen vacancies [73,74]. However, previous theoretical works related the defect $V_{O}$ with rather deep levels below CBM $[72,75]$, indicating that further exploration of the origin of the unintentional n-type conductivity of $\mathrm{ZnO}$ has to be conducted.

Recently, the native defects and the hydrogen impurity in $\mathrm{ZnO}$ were reinvestigated by Oba et al. [62], in which they calculated formation energy (total-energy-difference between defect and perfect systems) and the related transition levels for each kind of defects. The results were self-consistent and well consistent with the experimental ones.

Here, we first give a brief introduction to the concept of the transition level. The transition level is related to the total energies of the initial and final defect states of a particular type of transition [76]. As an example, we consider the transition $V_{O}^{0} \rightarrow V_{O}^{+}+e_{m}$, where $e_{m}$ is an ionized electron staying at 
some single electron state of energy $E^{\prime}\left(e_{m}\right)$. The total energy of the initial and final states of the transition of the multi-electron system considered here will be $E\left(V_{O}^{0}\right)$ and $E\left(V_{O}^{+}\right)+E^{\prime}\left(e_{m}\right)$, respectively. Considering the ionized electron $e_{m}$ is independent of the defect $\mathrm{V}_{\mathrm{O}}$, we can regard the transition in consideration as the transition of this particular electron $e_{m}$ by introducing an effective single electron energy level, so called transition level $\varepsilon(0 /+)$, namely, the transition can be expressed as $\varepsilon(0 /+) \rightarrow E^{\prime}\left(e_{m}\right)$ of the electron $e_{m}$. The level $\varepsilon(0 /+)$ is usually defined relative to the valence band top $E_{V}$ of the bulk $\mathrm{ZnO}$ and can be evaluated as follows. When the electron $e_{m}$ occupies the transition level, i.e. its energy $E_{\varepsilon}^{\prime}\left(e_{m}\right)=\varepsilon(0 /+)+E_{V}$, the equation $E\left(V_{O}^{0}\right)=E\left(V_{O}^{+}\right)+E_{\varepsilon}^{\prime}\left(e_{m}\right)$ holds. From the equation we can get $\varepsilon(0 /+)=E_{\varepsilon}^{\prime}\left(e_{m}\right)-E_{V}=\left[E\left(V_{O}^{0}\right)-E\left(V_{O}^{+}\right)\right]-E_{V}$. It can be clearly seen that the transition level contains the contribution of both multi-electron system $V_{O}^{0}$ and $V_{O}^{+}$. For the example discussed here the transition level $\varepsilon(0 /+)$ is positioned within the band gap. In general, the independent electron $e_{m}$ may sit at a single electron level of energy $E^{\prime}\left(e_{m}\right)=E\left(e_{m}\right)+E_{V}$, and then the excitation (ionization) energy of the system relative to the charge state $V_{O}^{0},\left[E\left(V_{O}^{+}\right)+E^{\prime}\left(e_{m}\right)\right]-E\left(V_{O}^{0}\right)$, can be determined to be $E\left(e_{m}\right)-\varepsilon(0 /+)$ [where both $E\left(e_{m}\right)$ and $\varepsilon(0 /+)$ are measured relative to VBM]. In particular, for the $e_{m}$ at $\operatorname{CBM}\left(E\left(e_{m}\right)=E_{g}\right)$, the excitation energy is just $E_{g}-\varepsilon(0 /+)$. For the reverse transition $V_{O}^{+}+e_{m} \rightarrow V_{O}^{0}$, similar discussion can be derived.

Now we can discuss the calculated results of Oba et al. Figure 11(a) [62] presents the formation energies as a function of the Fermi energy. The Fermi energy here is taken as the energy (chemical potential) of the reservoir from (in) which electrons are removed (placed) to form a charged defect [76], which is just the $E^{\prime}\left(e_{m}\right)$ in the case mentioned above. Usually the range of the Fermi energy is chosen to be in the range between the calculated valence-band maximum $(0 \mathrm{eV})$ and conduction-band minimum CBM (3.4 eV for bulk $\mathrm{ZnO}$ [62]). The formation energy of a defect in various charge states, say, $V_{O}^{+}$, contains the energy of the ionized electron $e_{m}$ and hence varies with the Fermi energy. In Figure 11(a), for each kind of defect, only the charge states that are energetically most favorable at a given Fermi energy are shown. The Fermi energies, at which the slopes change (where, for example, the formation energy of $V_{O}^{0}$ equals the formation energy of the defect state $V_{O}^{2+}$.), indicating happening of transition between the two charge states of the defect, correspond to the positions of thermodynamic transition levels (because the calculated total energy for each charge state corresponded to the completely relaxed atom-configuration). The resultant transition levels are depicted in Figure 11(b) together with the relevant charge states.

Notably, among the native donorlike defects, $V_{O}$ shows the lowest formation energy under most conditions. The formation energy for the neutral state $V_{O}^{0}$ is only $1.0 \mathrm{eV}$ at the oxygen-poor limit, which is low enough to account for the observed nonstoichiometry: e.g., 190 ppm for the specimen treated at $1373 \mathrm{~K}$.

Oba et al. [62] confirmed that for defect $V_{O}, \varepsilon(2+/+)$ lies above $\varepsilon(+/ 0)$ with $U=\varepsilon(+/ 0)-\varepsilon(2+/+)=-0.7 \mathrm{eV}$ (The defect is called a negative- $U$ center $)$. As the Fermi level moves from zero upward, the thermodynamic charge-state transition is thus directly from the $2+$ to the 0 charge state, since the formation energy of $V_{O}^{+}$is higher than that of $V_{O}^{0}$ and $V_{O}^{2+}$ for all values of $E_{F}$, so the charge state $V_{O}^{+}$is unstable for any position of the Fermi level. This negative- $U$ behavior is typically related to unusually large local lattice relaxations that stabilize particular charge states 
mentioned above, since these large relaxations significantly reduce the formation energies of $V_{O}^{2+}$ and $V_{O}^{0}$ relative to $V_{O}^{+}$. At the same time they provide a thermodynamic transition level $(2+/ 0)$ of $V_{O}$ at $1.2 \mathrm{eV}$ below the CBM, very close to the convergence value $1.0 \mathrm{eV}$ obtained by all methods that predict sufficiently large band gaps.

Figure 11. (a) Defect formation energies as a function of the Fermi energy at the oxygen-poor and oxygen-rich limits, (b) Defect thermodynamic transition levels. Reprinted from Ref. [62] with permission.
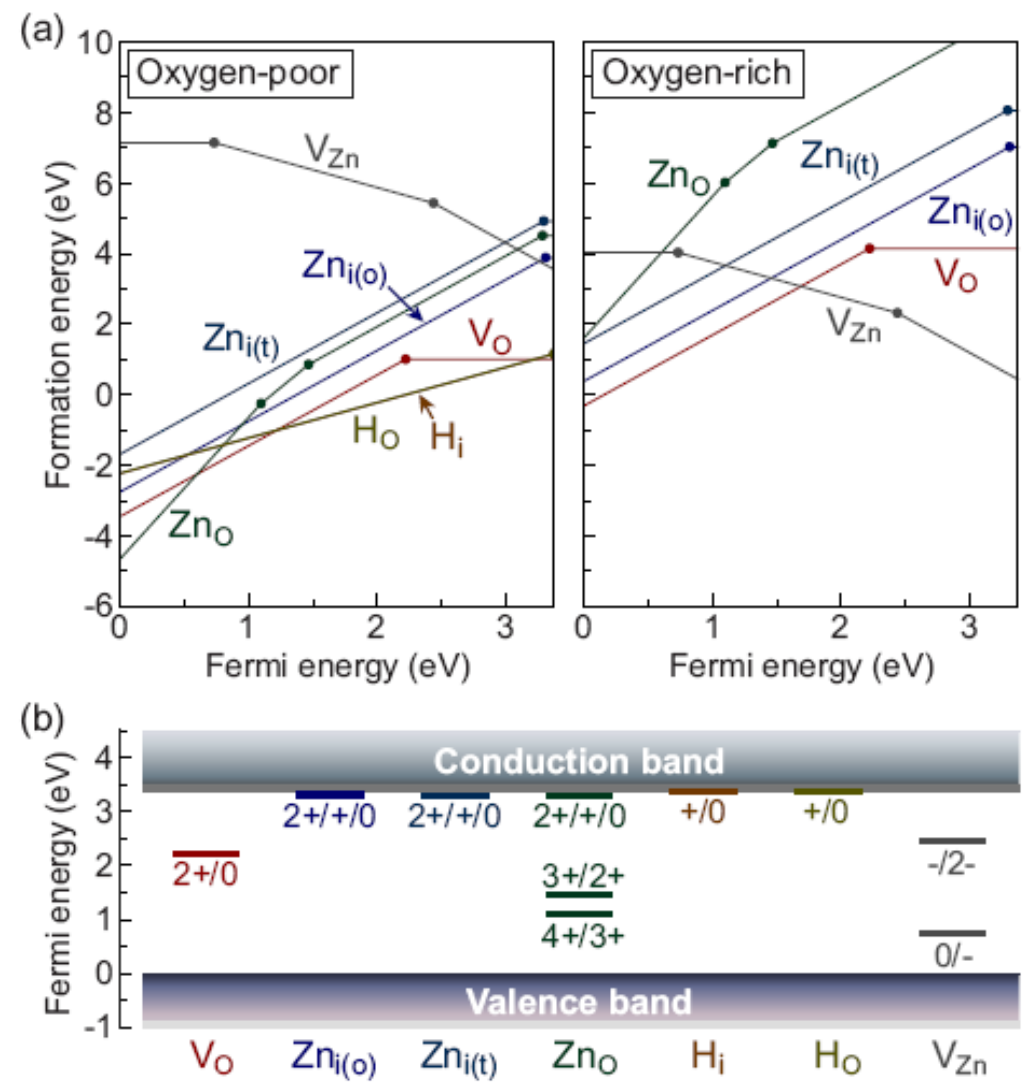

The zinc interstitials, $Z n_{i(\mathrm{o})}$ and $Z n_{i(\mathrm{t})}$, have transition levels located at 0.05 and $0.1 \mathrm{eV}$ below the $\mathrm{CBM}$, respectively. These levels are regarded here as the transition levels among the three charge states, $(2+/+/ 0)$, because the difference between the $(2+/+)$ and $(+/ 0)$ transition levels is comparable to the accuracy of the calculations. The possession of the $(2+/+/ 0)$ transition levels near the CBM indicates that the zinc interstitials are single or double shallow donors, which is consistent with the experimental report (donor energy: $0.03 \mathrm{eV}$ [77]). However, in these cases the formation energies are as high as 4 and $5 \mathrm{eV}$ even at the oxygen-poor limit. Therefore, the zinc interstitials are unlikely to form with a substantial concentration in $n$-type $\mathrm{ZnO}$.

$Z n_{O}$ also has a high formation energy under $n$-type conditions. It has a shallow $(2+/+/ 0)$ transition level and two other levels $(4+/ 3+)$ and $(3+/ 2+)$ located below the middle of the band gap.

Under the oxygen-poor condition and for a low Fermi energy, formation energy of $Z n_{O}$ is negative. It is the same for the other donorlike defects. A strong compensation of holes is therefore expected in $\mathrm{ZnO}$ grown under oxygen-poor conditions. 
For the hydrogen impurity, both $H_{i}$ and $H_{O}$ show (+/0) transition levels locating nearly on the CBM, as reported in all the studies. The formation energies are $1.2 \mathrm{eV}$ or lower, depending on the Fermi energy, which are close to an experimental estimate of $0.8 \mathrm{eV}$ [78] and as low as that of $V_{O}$ at the hydrogen-rich (oxygen-poor) limit. Therefore, their results support the proposed role as a shallow donor for the hydrogen impurity [79].

Since $V_{Z n}$ has high formation energy (between 3.5 and $7.1 \mathrm{eV}$ ), it is not expected to exert significant effects on the composition and carrier concentration, therefore a strong preference for the donorlike defects over acceptorlike $V_{Z n}$ under oxygen-poor conditions is found. This tendency is consistent with experimental observation of the nonstoichiometric and $n$-type behavior of $\mathrm{ZnO}$, but has not been reproduced by the previous calculations other than applying a posteriori band gap corrections to the LDA/GGA, as suggested in Ref. [75].

In summary, the recent theoretical work provides a clear picture of the defect energetics: among the donorlike defects, $V_{O}$ as a deep donor, and $H_{i}$ and $H_{O}$ as shallow donors, are likely to form with a substantial concentration in $n$-type $\mathrm{ZnO} . Z n_{i}$ and $Z n_{O}$ are shallow donors but their formation is energetically much less favorable. A strong preference for $V_{O}, H_{i}$, and $H_{O}$ over acceptorlike $V_{Z n}$ is expected under oxygen-poor conditions. It is therefore suggested that $V_{O}$ (and also $H_{O}$, which can be regarded as a complex of $V_{O}$ and $H_{i}$ ) should dominantly contribute to nonstoichiometry, and the hydrogen impurities, $H_{i}$ and $H_{O}$, and/or metastable $V_{O}$ with a shallow donor state (see below) can effectively act as donors, both without significant compensation by $V_{Z n}$. May be, this work constitutes a major step forward in modeling the complex behavior of semiconductors. To reach definite conclusion, further investigation, both theoretical and experimental investigations have to be conducted.

Now we turn to the discussion about the metastable $V_{O}$ shallow donor state mentioned above. S. Lany and A. Zunger [80] pointed out that at the defects $V_{O}$ in $\mathrm{ZnO}$ can take place a light-induced transition $V_{O}^{0} \rightarrow V_{O}^{2+}+2 e$, which results in metastable configuration change from nonconducting to conducting, constituting persistent electron photoconductivity ( $n$-type PPC). Their model can be described as follows: first, both electrons occupy the deep and nonconducting $a_{1}$-symmetry defect localized state (DLS) of the ground charge state $V_{O}^{0}\left(d_{\mathrm{Zn}-\mathrm{Zn}}=3.0 \AA\right)$. An optical excitation of energy $2.83 \mathrm{eV}$ makes the $V_{O}^{0}$ ground state transformed to the $V_{O}^{+}+e$ excited state. This transition creates $V_{O}^{+}\left(d_{\mathrm{Zn}-\mathrm{Zn}}=3.2 \AA\right)$ having a singly occupied DLS within the band gap, which is observed in EPR (electron paramagnetic resonance) experiments under illumination [81,82]. The second excitation $V_{O}^{+} \rightarrow V_{O}^{2+}+e$ of excitation energy $2.4 \mathrm{eV}$ creates the charge state $V_{O}^{2+}$ with equilibrium $d_{\mathrm{Zn}-\mathrm{Zn}}=4.0 \AA$. Accompanying this ionization and large outward relaxation, the $a_{1}$ DLS moves upward, becoming an unoccupied resonance state in the conduction band at $\left(E_{\mathrm{C}}+0.4\right) \mathrm{eV}$. At the same time, the ionized $V_{O}^{2+}$ creates a perturbed-host state (PHS) below the CBM by a long-range and screened Coulomb potential, which is a delocalized, hydrogen-like shallow state. Consequently, the photoexcited electrons occupy the lower energy PHS (rather than the DLS), thus a conducting configuration constituting $n$-type PPC is established. This light-induced configuration is metastable against the depopulation of electrons from the PHS into the deep ground state with small $d_{\mathrm{Zn}-\mathrm{Zn}}$ across an energy barrier.

Figure 12 shows the formation energies of the light-induced metastable configuration of $V_{O}^{0}$ and $V_{O}^{+}$(dashed lines) as a function of the Fermi energy $E_{\mathrm{F}}$, together with the corresponding formation 
energies in the respective equilibrium stable configuration (solid lines). The transition energies in the metastable configuration (open circles) are close to the CBM, so that this configuration is conductive.

One point to be noted is that there are two kinds of transition levels $\varepsilon_{t h}\left(q / q^{\prime}\right)$ and $\varepsilon_{o p}\left(q / q^{\prime}\right)$, the thermodynamic and optical ones. The former is used for describing thermodynamic equilibrium processes and so is defined as the difference of the total (or formation) energies of two charge states (thermodynamic equilibrium states) of a same kind of defect, which in it's definition are corresponding to the respective relaxed atomic configuration, and mostly have been calculated for $\mathrm{ZnO}$ [62]. The latter is used for optical transition, therefore both the total energies of the initial and final defect states are corresponding to the relaxed atomic configuration of the initial state [therefore the absorption transition level $\varepsilon_{o p}\left(q / q^{\prime}\right)$ is different from the emission transition level $\varepsilon_{o p}\left(q^{\prime} / q\right)$ for the same two charge states of the defect].

Figure 12. Formation energies of the different charge states of $V_{O}$ in $\mathrm{ZnO}$. Solid lines and closed circles show the formation and transition energies of the equilibrium stable states, respectively. Dashed lines and open circles show the formation and transition energies in the light-induced metastable configuration. Reprinted from Ref. [80] with permission.



\section{P-Type Doping}

The $n$-type $\mathrm{ZnO}$ is easily achieved even without intentional doping. However, the $p$-type $\mathrm{ZnO}$ is very difficult to prepare due to the compensation effect originating from native defects or background impurities, as well as the limited solubility and inactivation of the acceptor dopants in the $\mathrm{ZnO}$ films. Due to the lack of reliable, reproducible and stable p-type $\mathrm{ZnO}$ the progress in $\mathrm{ZnO}$-based devices has been limited. Intensive studies are continuously devoted to overcome this bottleneck.

It is well known that the acceptor dopants in $\mathrm{ZnO}$ include group-I elements such as Li [83-85], Na, and $\mathrm{K}$ [86,87], group-Ib elements $\mathrm{Cu}$ [88] and Ag [89-91], and group-V elements such as N, P, As and $\mathrm{Sb}$. Although it is theoretically suggested that group-I elements substituting for $\mathrm{Zn}$ possess shallow acceptor levels, it also appears that group-I elements, especially small size impurity such as Li, tend to occupy the interstitial sites (e.g., $\mathrm{Li}_{\mathrm{i}}$ ) which act as donor defects [92]. Much effort was focused on the controllable doping of group-I elements. Lu et al. [84,85] deposited Li-doped ZnO films by PLD with 
or without using ionization source. They found that $\mathrm{Li}$ atoms had a larger possibility to form $\mathrm{Li}_{\mathrm{Zn}}$ than $\mathrm{Li}_{\mathrm{i}}$, and this tendency was very strong under the oxygen-rich growth condition. The best result was obtained for $\mathrm{ZnO}: \mathrm{Li}$ at a 0.6 at \% Li content, which had the hole concentration of $6.04 \times 10^{17} \mathrm{~cm}^{-3}$, hall mobility of $1.75 \mathrm{~cm}^{2} / \mathrm{Vs}$, and resistivity of $5.9 \Omega \mathrm{cm}$. Wu and Yang [86] prepared K-doped $p$-ZnO thin films using rf magnetron sputtering technique under oxygen rich atmosphere. The optimal $p$-ZnO:K films possessed a higher hole concentration of $8.92 \times 10^{17} \mathrm{~cm}^{-3}$ and a lower resistivity of $1.8 \Omega \mathrm{cm}$. Ag-doped $\mathrm{ZnO}$ films were fabricated by PLD [89,90] and reaction sputtering [91], using $\mathrm{Ag}_{2} \mathrm{O}$ as the silver dopant, and p-type $\mathrm{ZnO}$ could only be obtained within a narrow deposition temperature window. A neutral acceptor bound exciton emission peak of $3.317 \mathrm{eV}$ was observed at $11 \mathrm{~K}$ [90]. Recently, several researchers have put efforts into the exploration of $p-\mathrm{ZnO}$ film by doping group-V elements as p-type dopants such as N [27,35,93], P [94-96] As [97-99], and Sb [100,101]. For group-V elements, Park et al. [92] have also given a prediction, by using first-principles pseudopotential method, that $\mathrm{P}$ and As are amphoteric: substitutional defects $\mathrm{P}_{\mathrm{O}}$ and $\mathrm{As}_{\mathrm{O}}$ are deep acceptors, but due to the size mismatching to $\mathrm{O}$, donor-like antisite defects $\mathrm{P}_{\mathrm{Zn}}$ and $\mathrm{As}_{\mathrm{Zn}}$ are more likely to form to avoid the build-up of local strains near the $\mathrm{O}$ site. They concluded that among these acceptors nitrogen dopant with a shallow acceptor level is a promising candidate to substitute for oxygen atoms as $\mathrm{N}_{\mathrm{O}}$ in the $\mathrm{ZnO}$ films because of the similar ionic radius and smallest ionization energy.

To date, $\mathrm{N}$-doped $\mathrm{ZnO}$ films have been prepared using various deposition methods such as chemical vapor deposition [27,102-104], spray pyrolysis [105], pulsed-laser deposition [106], implantation [107], and sputtering technology [108-110] using different nitrogen sources such as $\mathrm{N}_{2}, \mathrm{NH}_{3}, \mathrm{~N}_{2} \mathrm{O}$, $\mathrm{Zn}_{3} \mathrm{~N}_{2}$, and $\mathrm{MMH}_{y}$ (monomethyl hydrazine). However, the reliability and reproducibility in obtaining $p$-type $\mathrm{ZnO}: \mathrm{N}$ is still controversial. Because of the much higher chemical activity of $\mathrm{O}$ compared to that of $\mathrm{N}, \mathrm{Zn}$ is prone to combine with $\mathrm{O}$ rather than $\mathrm{N}$, resulting in the $\mathrm{N}$ atoms being difficult to be introduced into $\mathrm{ZnO}$ films. To solve this problem, Yamamoto and Yoshida [111] studied the "unipolarity" doping problem in $\mathrm{ZnO}$ crystal, based on the results of ab initio electronic band structure calculations and they found that while p-type doping using the $\mathrm{N}$ species leads to an increase in Madelung energy n-type doping using Al, Ga or In causes a decrease in Madelung energy. Then they proposed a codoping method, which use simultaneously nitrogen acceptors and reactive III-group donors as dopants complex such as $\mathrm{Ga}-\mathrm{N}, \mathrm{In}-\mathrm{N}$, and Al-N, to increase the solubility of $\mathrm{N}$ atoms in the $\mathrm{ZnO}$ films and lower the acceptor level in the band gap due to strong interaction between $\mathrm{N}$ acceptors and reactive donor codopants. In recent years, $p$-type $\mathrm{ZnO}$ films were comprehensively achieved by using the codoping method [35,112-119]. Compared with Ga and In atoms, Al is more suitable as reactive donors for their superior advantages such as low cost and near containment-free material as well as the superior stability for the strong $\mathrm{Al}-\mathrm{N}$ and $\mathrm{Al}-\mathrm{O}$ bonds.

In view of the formation of $\mathrm{Al}-\mathrm{N}$ codoped $p-\mathrm{ZnO}$ sensitive to the deposition condition, we proposed a controllable and well-configured rf magnetron co-sputtering method to prepare Al-N codoped $\mathrm{ZnO}$ films by using hexagonal $\mathrm{ZnO}$ and $\mathrm{AlN}$ as targets [20]. The rf magnetron co-sputtering system used in our lab is equipped with a dual rf power supply that generate two different rf powers with synchronized phases, which has been described in Section 2. With this method the doping concentration in the deposited $\mathrm{ZnO}$ films could be easily controlled by the co-sputtering rf power on each target. It is found that the measured $\mathrm{Al}$ atomic ratio $[\mathrm{Al} /(\mathrm{Zn}+\mathrm{Al})$ at \%] in the co-sputtered film decreases from 9.22-2.46 at. \%, when the rf power supplied on the $\mathrm{ZnO}$ target increases from 40 to 
$410 \mathrm{~W}$ and that on AlN target is fixed at $85 \mathrm{~W}$. The measured ratios are much smaller than the value theoretically evaluated from the deposition rates of the two targets, indicating the difficulty of incorporating AlN into $\mathrm{ZnO}$ films. The true atomic ratio of nitrogen to aluminum [N/Al in at \%] in the $\mathrm{AlN}-\mathrm{ZnO}$ co-sputtered films as a function of the rf co-sputtering power on the $\mathrm{ZnO}$ target is shown in Figure 13. The $\mathrm{N}$ atomic concentrations in these $\mathrm{Al}-\mathrm{N}$ codoped $\mathrm{ZnO}$ films are higher than the $\mathrm{Al}$ atomic concentrations, especially for the films prepared at elevated co-sputtering powers on the $\mathrm{ZnO}$ target. In spite of the higher ratio [N/Al], as-deposited $\mathrm{Al}-\mathrm{N}$ codoped $\mathrm{ZnO}$ films still show $n$-type conductive behavior, indicating the inactivity of $\mathrm{N}$ acceptor dopants in these $\mathrm{Al}-\mathrm{N}$ codoped films deposited at room temperature. It is found that only after an adequate post-annealing treatment the $\mathrm{N}$-related acceptor dopants are activated, and the resulting $\mathrm{ZnO}$ films exhibit $p$-type conductive behavior (Table 3).

Figure 13. Atomic concentration of nitrogen to aluminum $[\mathrm{N} / \mathrm{Al}]$ in the $\mathrm{AlN}-\mathrm{ZnO}$ cosputtered films as a function of the rf cosputtering power on $\mathrm{ZnO}$ target (the theoretical $\mathrm{Al}$ atomic ratio $[\mathrm{Al} /(\mathrm{Zn}+\mathrm{Al})$ at \%] is shown in bracket). Reprinted from Ref. [20] with permission.



Annealing at $300{ }^{\circ} \mathrm{C}$, the $\mathrm{Al}-\mathrm{N}$ codoped $\mathrm{ZnO}$ film performed $n$-type conduction with a slightly higher electron concentration than the as-deposited film. This indicated that $300{ }^{\circ} \mathrm{C}$ was too low to activate the N-related acceptors and more donors were generated. As the annealing temperature reached $400{ }^{\circ} \mathrm{C}$, the annealed $\mathrm{Al}-\mathrm{N}$ codoped $\mathrm{ZnO}$ film with a hole carrier concentration of $5.04 \times 10^{18} \mathrm{~cm}^{-3}$, mobility of $2.35 \mathrm{~cm}^{2} \mathrm{~V}^{-1} \mathrm{~s}^{-1}$, and resistivity of $0.527 \Omega \mathrm{cm}$ was obtained, whereas an undoped $\mathrm{ZnO}$ film annealed under the same conditions showed an electron concentration of $2.57 \times 10^{17} \mathrm{~cm}^{-3}$ and Hall mobility of $5.47 \mathrm{~cm}^{2} \mathrm{~V}^{-1} \mathrm{~s}^{-1}$. This implied that large amounts of N-related acceptors were effectively activated and predominated over the donors in the codoped film under this annealing condition. By further increasing the annealing temperature, more donor-related defects such as $V_{O}$ and $V_{N}$ were prone to be produced, resulting in a decrease in the hole concentration. In addition, the room temperature PL spectrum also showed the features related to the activated N-related acceptors: the $60 \mathrm{meV}$ redshift of the shallow level transition (from $3.07 \mathrm{eV}$ in undoped $\mathrm{ZnO}$ film to $3.01 \mathrm{eV}$ ) and the suppression of oxygen-related deep level emission (2.11 eV) (Figure 14). 
Table 3. Electrical properties of the Al-N codoped $\mathrm{ZnO}$ films [theoretical $\mathrm{Al}$ atomic ratio of $10 \%$ ] deposited on silicon substrates annealed at various temperatures under nitrogen ambient for $30 \mathrm{~min}$. Reprinted from Ref. [20] with permission.

\begin{tabular}{lcccc}
\hline $\begin{array}{l}\text { Annealing } \\
\text { temperature }\end{array}$ & $\begin{array}{c}\text { Carrier concentration } \\
\left(\mathrm{cm}^{-3}\right)\end{array}$ & $\begin{array}{c}\text { Mobility } \\
\left(\mathrm{cm}^{2} \mathrm{~V}^{-1} \mathrm{~s}^{-1}\right)\end{array}$ & $\begin{array}{c}\text { Resistivity } \\
(\Omega \mathrm{cm})\end{array}$ & $\begin{array}{c}\text { Carrier } \\
\text { type }\end{array}$ \\
\hline As-deposited & $8.99 \times 10^{18}$ & 0.96 & 1.97 & $n$ \\
$300{ }^{\circ} \mathrm{C}$ & $1.49 \times 10^{19}$ & 0.83 & 1.38 & $n$ \\
$400{ }^{\circ} \mathrm{C}$ & $5.04 \times 10^{18}$ & 2.35 & 0.527 & $p$ \\
$500{ }^{\circ} \mathrm{C}$ & $1.04 \times 10^{18}$ & 3.64 & 1.65 & $p$ \\
$600^{\circ} \mathrm{C}$ & $1.53 \times 10^{17}$ & 5.03 & $1.34 \times 10^{1}$ & $p$ \\
$700^{\circ} \mathrm{C}$ & $5.88 \times 10^{15}$ & 6.58 & $1.62 \times 10^{2}$ & $p$ \\
\hline
\end{tabular}

Figure 14. Room temperature PL spectra of the Al-N codoped [theoretical Al atomic ratio of $10 \%$ ] and undoped $\mathrm{ZnO}$ films deposited on silicon substrates annealed at $400{ }^{\circ} \mathrm{C}$ under nitrogen ambient for 30 min. Reprinted from Ref. [20] with permission.

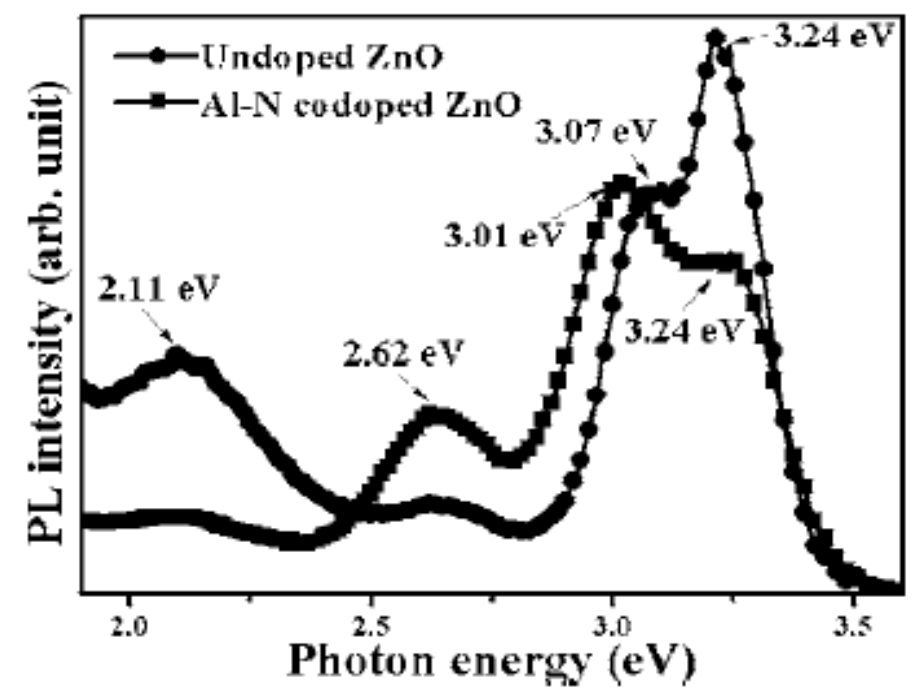

In order to improve the quality of $p$-type $\mathrm{ZnO}$ codoped with $\mathrm{AlN}$ and study the function of nitrogen in these films in more detail, we [120] prepared a series of AlN codoped $\mathrm{ZnO}$ films using the same radio frequency (rf) magnetron cosputtering system, but under various $\mathrm{N}_{2} /\left(\mathrm{N}_{2}+\right.$ Ar) flow ratios and with lower $\mathrm{rf}$ power. The rf powers of $\mathrm{AlN}$ and $\mathrm{ZnO}$ were fixed at 25 and $100 \mathrm{~W}$, respectively, and the $\mathrm{N}_{2} /\left(\mathrm{N}_{2}+\right.$ Ar) flow ratios of $0 \%, 4 \%, 8 \%$, and $12 \%$ were used with the total flow rate kept at $50 \mathrm{sccm}$ Then the prepared samples were post-annealed at 400,450 , and $500{ }^{\circ} \mathrm{C}$ for $10 \mathrm{~min}$ in a $\mathrm{N}_{2}$ ambient to activate the doping impurities. The electronic properties of samples deposited in various atmospheres and annealed at different temperatures are listed in Table 4. The highest electron concentration of samples $\mathrm{B}$ would be attributed to the effective substitution of $\mathrm{Zn}$ sites by $\mathrm{Al}$ atoms provided by cosputtering AlN, which also implied that at the deposition condition of B group (under pure Ar ambient) not enough $\mathrm{N}$ acceptors were formed. In other words, the formation of $\mathrm{Zn}-\mathrm{N}$ bonds was not preferential in an insufficient $\mathrm{N}$ atmosphere. The sample with a lower annealing temperature of $400{ }^{\circ} \mathrm{C}$ in group $\mathrm{C}$ exhibited n-type conductive behavior. With the same annealing temperature, the samples in groups $\mathrm{D}$ and $\mathrm{E}$, deposited under higher $\mathrm{N}_{2} /\left(\mathrm{N}_{2}+\right.$ Ar) flow ratios, exhibited a high resistivity and 
ambiguous carrier type. However, with the intermediate post-annealing temperature at $450{ }^{\circ} \mathrm{C}$, the deposited films of groups $\mathrm{C}, \mathrm{D}$, and $\mathrm{E}$ were converted from $\mathrm{n}$-type into p-type conduction, indicating that the N-related acceptor dopants were activated properly by the annealing treatment at this temperature. The fact that samples $\mathrm{D}$ and $\mathrm{E}$ deposited under a higher $\mathrm{N}_{2} /\left(\mathrm{N}_{2}+\right.$ Ar) flow ratio have a lower hole concentration was due to the self-compensation induced by the higher $\left(\mathrm{N}_{2}\right)_{\mathrm{O}}$ concentration within $\mathrm{ZnO}$ films. Moreover, the phenomenon that the carrier type of samples in $\mathrm{C}, \mathrm{D}$, and $\mathrm{E}$, annealed at a higher temperature of $500{ }^{\circ} \mathrm{C}$, changed from p-type to n-type was assumed to the dissociation of $\mathrm{Zn}-\mathrm{N}$ bonds and the formation of native defects, such as oxygen vacancies.

Table 4. Resistivity, Hall mobility, carrier concentration, and carrier type measured by Hall measurement for films deposited at various conditions. Reprinted from Ref. [20] with permission.

\begin{tabular}{cccccccc}
\hline $\begin{array}{c}\text { Sample group } \\
\text { ID }\end{array}$ & Target & $\begin{array}{c}\text { Gas } \\
(\mathrm{sccm})\end{array}$ & $\begin{array}{c}\text { Post-annealing } \\
\text { temperature }\end{array}$ & $\begin{array}{c}\text { Resistivity } \\
(\Omega-\mathrm{cm})\end{array}$ & $\begin{array}{c}\text { Hall mobility } \\
\left(\mathrm{cm}^{2} / \mathrm{V}-\mathrm{s}\right)\end{array}$ & $\begin{array}{c}\text { Carrier concentration } \\
\left(\mathrm{cm}^{-3}\right)\end{array}$ & $\begin{array}{c}\text { Carrier } \\
\text { type }\end{array}$ \\
\hline & & & $400{ }^{\circ} \mathrm{C}$ & $3.67 \times 10^{-1}$ & 3.66 & $4.61 \times 10^{18}$ & $\mathrm{n}$ \\
$\mathrm{A}$ & $\mathrm{ZnO}$ & $\mathrm{Ar}: 50$ & $450{ }^{\circ} \mathrm{C}$ & $2.74 \times 10^{-1}$ & 4.71 & $4.83 \times 10^{18}$ & $\mathrm{n}$ \\
& & & $500^{\circ} \mathrm{C}$ & $2.09 \times 10^{-1}$ & 4.79 & $6.57 \times 10^{18}$ & $\mathrm{n}$ \\
& $\mathrm{ZnO}$ & & $400{ }^{\circ} \mathrm{C}$ & $1.45 \times 10^{-1}$ & 4.02 & $1.07 \times 10^{19}$ & $\mathrm{n}$ \\
$\mathrm{B}$ & $\mathrm{AlN}$ & $\mathrm{Ar}: 50$ & $450^{\circ} \mathrm{C}$ & $2.92 \times 10^{-2}$ & 4.42 & $4.85 \times 10^{19}$ & $\mathrm{n}$ \\
& & & $500^{\circ} \mathrm{C}$ & $2.73 \times 10^{-2}$ & 4.64 & $4.95 \times 10^{19}$ & $\mathrm{n}$ \\
& $\mathrm{ZnO}$ & $\mathrm{Ar}: 48$ & $400{ }^{\circ} \mathrm{C}$ & 7.44 & 1.56 & $7.23 \times 10^{17}$ & $\mathrm{n}$ \\
$\mathrm{C}$ & $\mathrm{AlN}$ & $\mathrm{N}_{2}: 2$ & $450^{\circ} \mathrm{C}$ & 3.88 & 1.35 & $1.17 \times 10^{18}$ & $\mathrm{p}$ \\
& & & $500^{\circ} \mathrm{C}$ & $1.67 \times 10^{-1}$ & 4.42 & $8.31 \times 10^{18}$ & $\mathrm{n}$ \\
& $\mathrm{ZnO}$ & $\mathrm{Ar}: 46$ & $400{ }^{\circ} \mathrm{C}$ & $1.39 \times 10^{4}$ & 3.51 & $1.28 \times 10^{14}$ & $\mathrm{p} / \mathrm{n}$ \\
$\mathrm{D}$ & $\mathrm{AlN}$ & $\mathrm{N}_{2}: 4$ & $450{ }^{\circ} \mathrm{C}$ & $6.12 \times 10^{2}$ & 1.24 & $8.21 \times 10^{15}$ & $\mathrm{p}$ \\
& & & $500^{\circ} \mathrm{C}$ & $1.53 \times 10^{1}$ & 4.13 & $9.92 \times 10^{15}$ & $\mathrm{n}$ \\
& $\mathrm{ZnO}$ & $\mathrm{Ar}: 44$ & $400{ }^{\circ} \mathrm{C}$ & $1.28 \times 10^{4}$ & 2.12 & $2.28 \times 10^{14}$ & $\mathrm{p} / \mathrm{n}$ \\
$\mathrm{E}$ & $\mathrm{AlN}$ & $\mathrm{N}_{2}: 6$ & $450^{\circ} \mathrm{C}$ & $1.13 \times 10^{3}$ & 3.14 & $1.76 \times 10^{15}$ & $\mathrm{p}$ \\
& & & $500^{\circ} \mathrm{C}$ & $2.81 \times 10^{2}$ & 3.25 & $6.95 \times 10^{15}$ & $\mathrm{n}$ \\
\hline
\end{tabular}

All these suppositions were confirmed by the results of XRD, low temperature PL spectra (LTPL) and time-resolved PL spectra (TRPL) measurements. Figure 15(a) shows the LTPL spectra of undoped and $\mathrm{AlN}$ codoped $\mathrm{ZnO}$ films post-annealed at $450{ }^{\circ} \mathrm{C}$ in $\mathrm{UV}$ range. The emission peak at 3.362 and $3.315 \mathrm{eV}$ of sample $\mathrm{A}$ and $\mathrm{B}$ were assigned as the neutral donor bound exciton $\left(\mathrm{D}^{\circ} \mathrm{X}\right)$ and donor-acceptor pair (DAP) transition, respectively. A new strong peak at $3.332 \mathrm{eV}$ clearly observed for samples $\mathrm{C}, \mathrm{D}$, and $\mathrm{E}$ was attributed to the neutral acceptor bound exciton $\left(\mathrm{A}^{\circ} \mathrm{X}\right)$, while the peak at $3.278 \mathrm{eV}$ was labeled as the recombination emissions of free electron to acceptor hole level (FA) due to the nitrogen in the oxygen site $\mathrm{N}_{\mathrm{O}}$. LTPL in deep level emission range of $\mathrm{ZnO}, \mathrm{AlN}-\mathrm{ZnO}\left[\mathrm{N}_{2} /\right.$ $\left.\left(\mathrm{N}_{2}+\mathrm{Ar}\right)=0 \%, 4 \%, 8 \%, 12 \%\right]$ films annealed at $450{ }^{\circ} \mathrm{C}$ are shown in Figure $15(\mathrm{~b})$. Two emission bands at 2.35 and $1.89 \mathrm{eV}$, corresponding presumably to oxygen vacancies and oxygen interstitials, respectively, in sample B were weaker than that in sample A, implying less oxygen defects existed in sample B. This fact suggested that the higher electron concentration of sample B (listed in Table 4) might be attributed to the substitutional $\mathrm{Al}$ atoms on $\mathrm{Zn}$ sites instead of oxygen vacancies. 
Figure 15. LTPL spectra $(10 \mathrm{~K})$ of $\mathrm{ZnO}$ and $\mathrm{AlN}-\mathrm{ZnO}\left[\mathrm{N}_{2} /\left(\mathrm{N}_{2}+\mathrm{Ar}\right)=0 \%, 4 \%, 8 \%, 12 \%\right]$ films annealed at $450{ }^{\circ} \mathrm{C}$ (a) in UV emission range. (b) in deep level emission range. (c) LTPL spectra of the AlN-ZnO $\left[\mathrm{N}_{2} /\left(\mathrm{N}_{2}+\mathrm{Ar}\right)=4 \%\right.$ films annealed at 400,450 , and $500{ }^{\circ} \mathrm{C}$, respectively. Reprinted from Ref. [120] with permission.
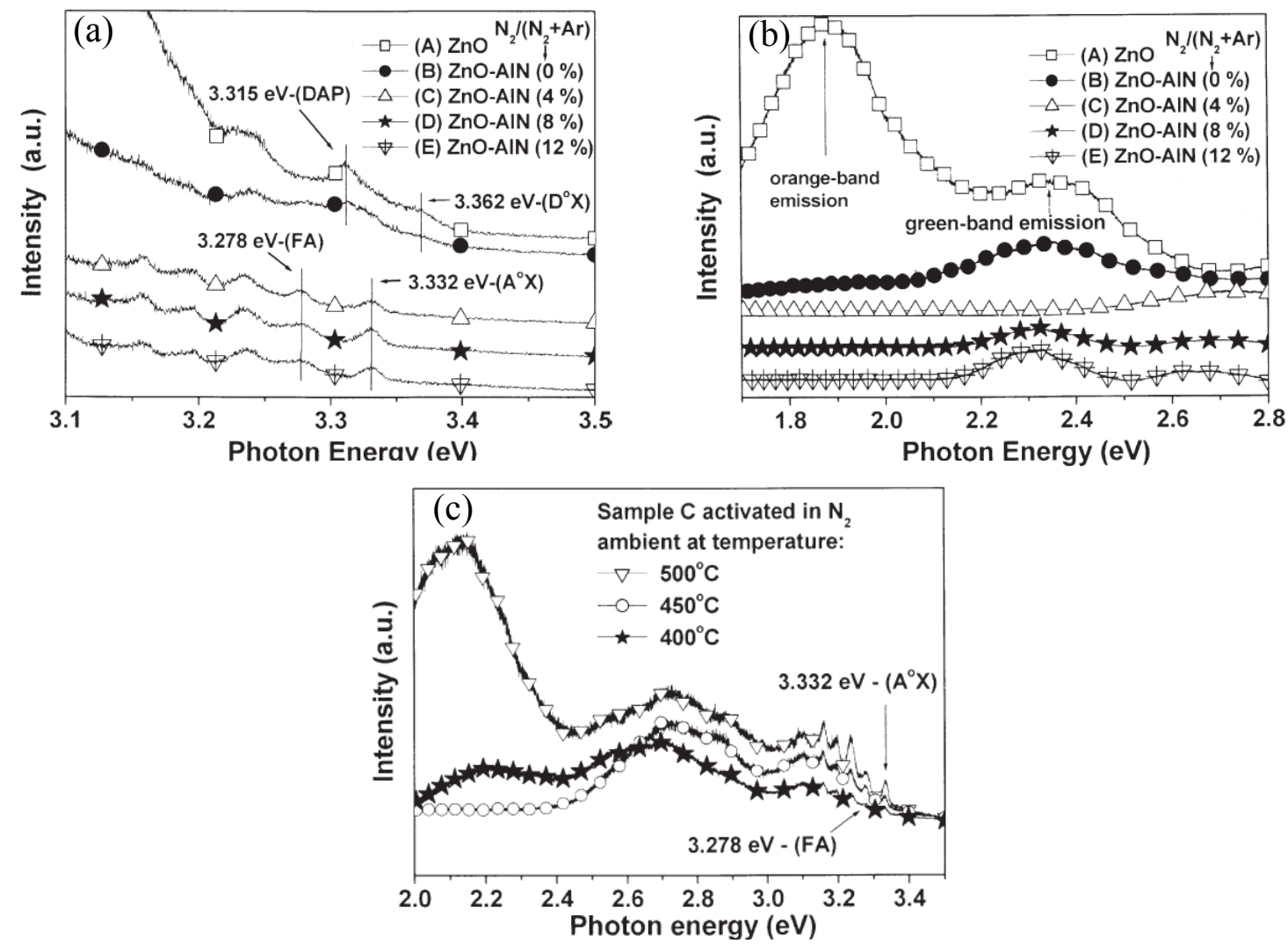

Compared to the case of the sample $\mathrm{C}$, more $\mathrm{N}_{2}$ on $\mathrm{O}$ substitution sites $\left(\mathrm{N}_{2}\right)_{O}$ simultaneously existed in samples $\mathrm{D}$ and $\mathrm{E}$, which resulted in the larger lattice constants as identified by the XRD experimental results (not shown here). This was consistent with the fact that samples D and E were deposited under higher $\mathrm{N}_{2} /\left(\mathrm{N}_{2}+\right.$ Ar) flow ratios. Furthermore, the fact that the intensity of $2.35 \mathrm{eV}$ emission band in samples $\mathrm{D}$ and $\mathrm{E}$ is higher than that in sample $\mathrm{C}$ implies more $\mathrm{O}$ vacancies existed in samples D and E, which can be tentatively interpreted as the result of compensation for the existence of more $\left(N_{2}\right)_{O}$ in the film. Because both $\mathrm{O}$ vacancies and $\left(N_{2}\right)_{O}$ serve as donors in $\mathrm{ZnO}$ film, $\mathrm{N}$ acceptors formed in samples D and E were partly compensated by them and resulted in a lower hole concentration as seen in Table 4. Figure $15(\mathrm{c})$ is the LTPL spectra of sample $C\left(\left[\mathrm{~N}_{2} /\left(\mathrm{N}_{2}+\mathrm{Ar}\right)=4 \%\right]\right)$ annealed at 400,450 , and $500{ }^{\circ} \mathrm{C}$, respectively. The broad blue-green emission band around 2.4-2.8 eV was originated from the deep level caused by the dopant-induced defects. The other broad deep level emission at $2.15 \mathrm{eV}$ was regarded as the oxygen-related emission. As shown in Figure 15(c), the emission induced by the dopant increased and the oxygen-related emission decreased, when the annealing temperature increased from 400 to $450{ }^{\circ} \mathrm{C}$ for sample $\mathrm{C}$. This implies that more nitrogen atoms occupied the oxygen vacancy sites to form $\mathrm{N}_{\mathrm{O}}$ acceptors, which interprets the stable p-type behavior for the sample in group $\mathrm{C}$ annealed at $450{ }^{\circ} \mathrm{C}$. The degradation of the $p$-type behavior for samples annealed at higher temperatures was attributed to the dissociation of $\mathrm{Zn}-\mathrm{N}$ bonds and $\mathrm{Zn}-\mathrm{O}$ bonds. 
The results discussed above lead us to the conclusion that high quality $p$-type ZnO films can be obtained by co-sputtering of $\mathrm{ZnO}$ and $\mathrm{AlN}$ under an adequate $\mathrm{N}_{2} /\left(\mathrm{N}_{2}+\right.$ Ar) flow ratio of $4 \%$ and post-annealing at $450{ }^{\circ} \mathrm{C}$.

\section{Nanostructured ZnO Materials}

It is well known that nanometer semiconductor may have superior optical and electrical properties than bulk crystals owing to quantum confinement effects. Great efforts have been devoted to the nano-science and technology in the world. Nanostructured $\mathrm{ZnO}$ is also a hot topic in the research community, especially one-dimentional (1D) $\mathrm{ZnO}$ nanostructures. Large amount of research reports on 1D nanostructured $\mathrm{ZnO}$ of different shapes have been published and comprehensively reviewed [121]. Here we will not review all the aspects of the attracting field but just focus on limited topics. Many methods have been used to obtain $\mathrm{ZnO}$ Nanowires or nanorods. For example, Lee et al. [122] have used MOCVD to grow well-aligned, single-crystalline $\mathrm{ZnO}$ nanowires on GaAs substrates. Yuan et al. [123] reported that well-aligned $\mathrm{ZnO}$ nanowire $(\mathrm{NW})$ arrays with durable and reproducible p-type conductivity were synthesized on sapphire substrates via vapor-liquid-solid growth by using $\mathrm{N}_{2} \mathrm{O}$ as a dopant source. Low-temperature growth routes for $\mathrm{ZnO}$ nanorods have also been reported [124,125]. 2D $\mathrm{ZnO}$ nanostructures have large surface area and thus are suitable for potential applications in nanoscale optoelectronics, sensors, dye-sensitized solar cells, and light emitters etc.

In our lab, several deposition methods have been used to grow nanostructured $\mathrm{ZnO}$ layers, such as low pressure vapor phase transport process [126], carbothermal reduction, deposition using vapor cooling condensation through porous Al template, and hydrothermal method.

We fabricated In-doped $\mathrm{ZnO}$ nanodisks (Figure 16) by carbothermal reduction [59], and found that the In doping seems to increase the activation energy required for the growth unit joining with the (0002) surface, resulting in the suppression of the growth along the [0001] direction. But the air-cooled (cooled in air after growth by taking the samples off the furnace) $\mathrm{ZnO}$ nanodisks showed a very strong green emission, which can be attributed to the defects produced by In doping. However, furnace cooling (naturally cooled to room temperature in the furnace) in conjunction with introducing $\mathrm{O}_{2}$, around 1.0\%, into flowing Ar during growth significantly enhanced the growth rate and UV emission of $\mathrm{ZnO}$ nanodisks, while the green emission was significantly suppressed when the oxygen concentration was increased from 0.5 to $1 \%$. The latter can be attributed to the reduction of oxygen vacancies and surface defects in $\mathrm{ZnO}$ nanodisks. It is noticed that when the oxygen concentration was increased to $10 \%$, the intensity of UV emission was considerably reduced. It is conceived that at a higher oxygen partial pressure many $\mathrm{Zn}$ vacancies may form in the $\mathrm{ZnO}$ nanodisks, resulting in suppression of UV emission.

$\mathrm{ZnO}$ nanorod arrays with different densities and sizes were also fabricated by using a chemical vapor transport process in our lab [31]. The source material, Zn powder (purity 99.5\%), was placed at the sealed end of quartz tube in a furnace. The system was maintained at a pressure of about 30 Torr. Argon gas was used as the carrier gas with a constant flow rate of $200 \mathrm{sccm}$. Oxygen gas with $30 \mathrm{sccm}$ flow rate was introduced into the furnace at $450{ }^{\circ} \mathrm{C}$. Samples A, B, C, and D were placed at $\sim 13,18$, 23 , and $28 \mathrm{~cm}$ from the center of furnace with their temperatures being $\sim 640,630,560$, and $470{ }^{\circ} \mathrm{C}$, respectively. The $\mathrm{Zn}$ source was maintained at $650{ }^{\circ} \mathrm{C}$ for $30 \mathrm{~min}$. Then the furnace was cooled down to room temperature naturally. 
Figure 16. SEM images of $\mathrm{ZnO}$ nanodisks grown at $1000{ }^{\circ} \mathrm{C}$ in flowing $\mathrm{Ar}(99 \mathrm{sccm}) / \mathrm{O}_{2}$ (1 sccm) and then subjected to furnace cooling. Reprinted from Ref. [59] with permission.

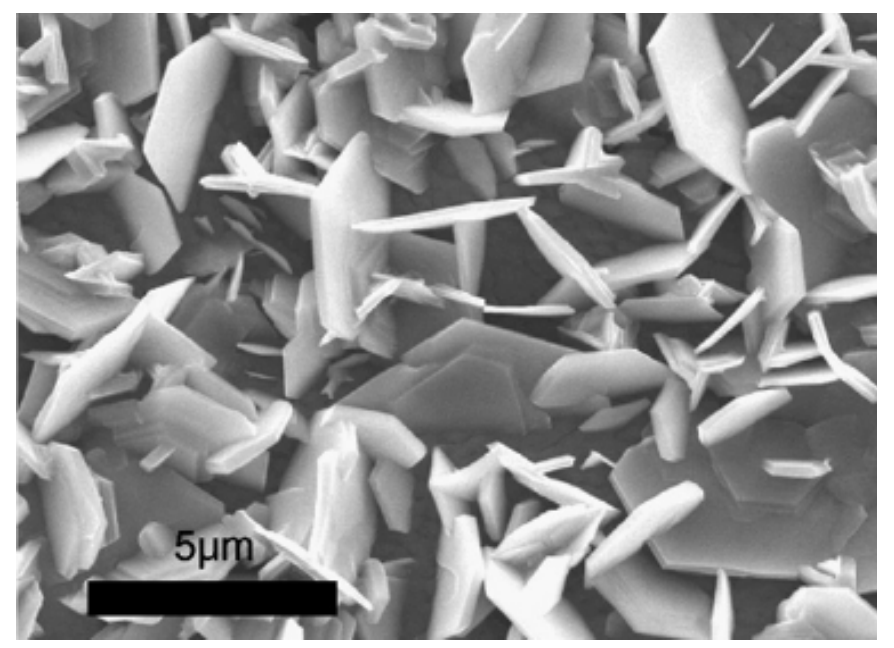

Figure 17 shows SEM images of the samples A, B, C, and D. Sample A consists of micropyramids on the Si substrate. Short nanorods formed only on the tips of some of micropyramids. Sample B consists of micropyramids with thin nanorods on their tips. Sample C shows high-density ZnO nanorod arrays on the tips of small micropyramids. However, the morphology of sample D differs from the other samples. The tip size of the nanorods grown on the pyramids is larger than the root size. The growth mechanism of nanorod array was analyzed. In brief, the population of $\mathrm{ZnO}$ nanorods was controlled by the secondary growth of nanorods on the tips of primarily grown pyramids. The hexagonal prisms and consequent pyramids are attributed to the difference in the growth rate of different crystal planes. The overgrowth of $\mathrm{ZnO}$ nanorods on the micropyramidal tips is due to the orientation adhesion. The density and size of these nanorods are influenced by the difference of saturation pressure at different temperature and the transport of source material by the carrying gas. The dense nanorods with small size exhibited excellent field emission properties.

We also fabricated vertically well-aligned $\mathrm{ZnO}$ nanowires by spin-on-glass technology on $\mathrm{ZnO}: \mathrm{Ga} /$ glass templates [127], which has been used for constructing photodetectors.

In addition to the preparation of the nanostrutured $\mathrm{ZnO}$, their optical properties are another important issue to be exploited. Generally the optical properties of nanostructured semiconductors depend strongly on their size and shape [128], which is a crucial issue in nanophysics due to their role in carrier relaxation [129] and very important for many applications such as single photon source [130] and high frequency acoustic emitter etc [131]. For example, Fonoberov et al. studied theoretically the optical properties of zero-dimensional $\mathrm{ZnO}$ nanostructures or quantum dots (QDs). They found that depending on the fabrication technique and $\mathrm{ZnO}$ QD surface quality, the origin of UV photoluminescence in $\mathrm{ZnO}$ QDs with diameters from 2-6 nm was due to the recombination of either confined excitons or surface-bound ionized acceptor-exciton complexes. In the latter case the Stokes shift of about 100-200 meV was observed in the photoluminescence spectrum. They also found that the radiative lifetime of the confined exciton and that of the ionized donor-exciton complex were almost the same. The lifetimes in both cases decreased with QD size and were about an order of magnitude less (for QD of radius $R \sim 2 \mathrm{~nm}$ ) than the bulk exciton lifetime. For the QD with diameter $5 \mathrm{~nm}$ the lifetime of $38 \mathrm{ps}$ was obtained, in agreement with the conclusion of Bahnemann et al. [132]. 
This is beneficial for optoelectronic device applications. On the other hand, the radiative lifetime of the ionized acceptor-exciton complex increased with QD size very fast, particularly for QD of $R \sim 2 \mathrm{~nm}$, the lifetime was about two orders of magnitude larger than the bulk exciton lifetime. Thereby they proposed to use the exciton radiative lifetime as a probe of the exciton localization. Laser action from nanostructured $\mathrm{ZnO}$ is another interesting topic that has been studied widely. As an example, X.H. Han et al. [133] demonstrated the lasing from high density well-aligned $\mathrm{ZnO}$ nanorod arrays synthesized by an improved vapor transport method on $\mathrm{ZnO}$ thin films.

Figure 17. SEM images of samples A, B, C, and D grown at (a) 640, (b) 630, (c) 560 and (d) $470{ }^{\circ} \mathrm{C}$, respectively. The magnifications are 5000 for a, b, and d and 10000 for $\mathrm{c}$. Reprinted from Ref. [31] with permission.



Short wavelength luminescence of nanostructured $\mathrm{ZnO}$ is of great interest due to its potential optoelectronic application. Because of its fundamental importance we studied exciton related interaction in the $\mathrm{ZnO}$ nanostructure. We successfully fabricated high quality $\mathrm{ZnO}$ nanowires with a diameter of about $70 \mathrm{~nm}$ and $1000 \mathrm{~nm}$ in length on Si (100) substrates by a low pressure vapor phase transport process [127], and then studied the free excitonic transition in individual $\mathrm{ZnO}$ nanowires. Figure 18(a) shows the PL spectrum of $\mathrm{ZnO}$ nanowires measured at $10 \mathrm{~K}$, in which strong near-band-edge (NBE) emission peaks are observed, and deep level visible emissions relating to structural defects are almost negligible. This fact suggests a low defect density for the as-grown nanowires. The clear observation of the FX peak (at $3.375 \mathrm{eV})$, the neutral-donor bound exciton $\left(D^{0} X\right.$ at $3.359 \mathrm{eV}$ ), the 1-LO(71 meV), 2-LO, 3-LO, and 4-LO phonon replicas of donor acceptor pair (DAP at $3.315 \mathrm{eV}$ ) transition, and the peaks at high energy shoulder (attributed to bound excitons at different unintentional impurities) further indicates (besides the FE-SEM image and the XRD pattern ) that $\mathrm{ZnO}$ nanowires are of high optical quality. 
Figure 18. $\mathrm{PL}$ spectrum of $\mathrm{ZnO}$ nanowires measured at $10 \mathrm{~K}$, (a) for photon energy ranging from $1.77-3.5 \mathrm{eV}$. The inset is the part in the near-band edge region (3.0-3.4 eV) in a magnified scale. (b) High resolution high energy shoulder in near-band edge emission. Reprinted from Ref. [126] with permission.

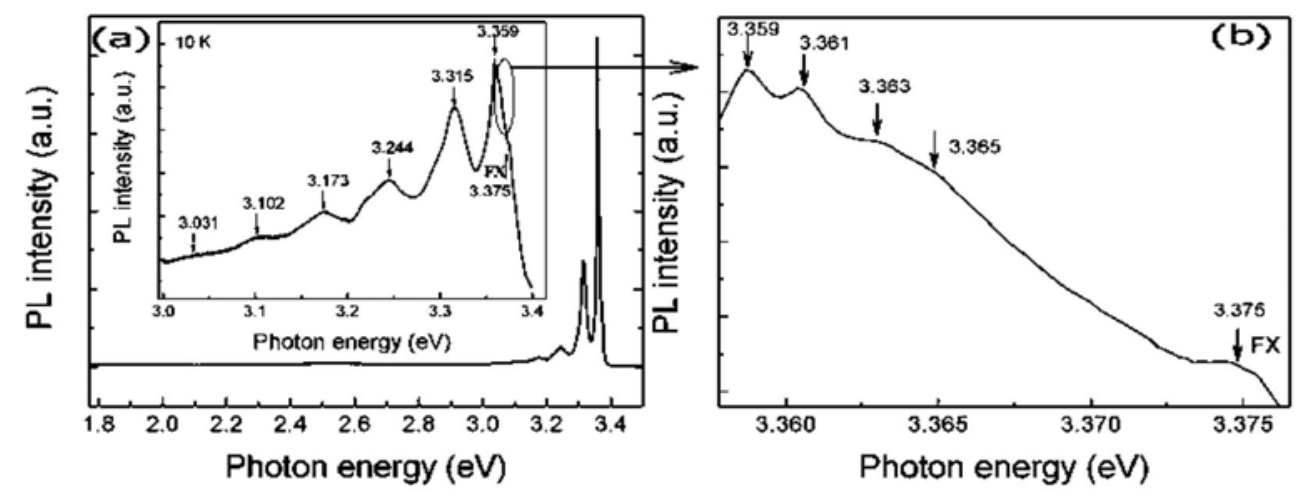

\section{ZnO Based Light Emitting Diodes}

Due to the progress in preparation of $\mathrm{ZnO}$ materials, especially $p$ - $\mathrm{ZnO}$ materials, more research efforts have been devoted to the exploration of various $\mathrm{ZnO}$-based short wavelength light-emitting diodes. The progress in the aspect goes ahead continuously and new improvements have been demonstrated in recent years, as summarized in a recent publication [134].

Firstly, the exploration of $\mathrm{ZnO} p-n$ homojunction LEDs is still an attractive research topic. The progress achieved in this direction is closely related to the improvement in preparation of $p$-type $\mathrm{ZnO}$ materials. It is not difficult to list a few newly reported examples of $\mathrm{ZnO} p$ - $n$ junction LEDs, where $p-\mathrm{ZnO}$ was obtained by using different dopants, such as $\mathrm{NO}$ [135], $\mathrm{N}_{2} \mathrm{O}$ [136], $\mathrm{N}_{2}-\mathrm{O}_{2}$ [137], N-Al [138], N-In [139], and Sb [101]. Various deposition methods, including plasma-assisted molecular beam epitaxy, dc reactive magnetron sputtering, MOCVD, ultrasonic spray pyrolysis and so on were used to deposit the $\mathrm{ZnO}$ layers. In most cases, the resulting $\mathrm{ZnO} p$ - $n$ junction LEDs emitted blue-violet electroluminescence under forward bias at low temperature, which was attributed to donor-acceptor pair recombination in $p-\mathrm{ZnO}$. Some works also reported the emission from deep defect levels. It is noted that device performance improved, but the EL was still quenched substantially at room temperature. This can be ascribed to the imperfection of the $p-\mathrm{ZnO}$.

In view of the fact that the high quality $p-\mathrm{ZnO}$ is still not available, many efforts have continuously focused on an alternative type of device structures, the $n$-ZnO based heterojunction (e.g., [140]), in which the active $n$ - $\mathrm{ZnO}$ layer is deposited on other $p$-type materials to form $n$-ZnO based $p$ - $n$ junction LEDs.

Rogers et al. [141] fabricated a $n-\mathrm{ZnO} / p$-GaN:Mg heterojunction LED on $c-\mathrm{Al}_{2} \mathrm{O}_{3}$ substrates using pulsed laser deposition for the $\mathrm{ZnO}$ and metal organic chemical vapor deposition for the $\mathrm{GaN}: \mathrm{Mg}$. Room temperature electroluminescence of the LED showed an emission peaked at $375 \mathrm{~nm}$, the same as the photoluminescence of the $\mathrm{ZnO}$ layer, indicative of a near band edge excitonic emission. Over the injection current range from $500-875 \mathrm{~mA}$ the light-current $(L-I)$ characteristic of spectral intensity versus current appears fairly linear.

Long et al. [142] reported that ultraviolet light-emitting diodes based on $\mathrm{ZnO} / \mathrm{NiO}$ heterojunctions 
were fabricated on commercially available $n^{+}-\mathrm{GaN} /$ sapphire substrates using a radio frequency magnetron sputtering system. Near band edge emission of $\mathrm{ZnO}$ peaking at $370 \mathrm{~nm}$ was achieved at room temperature when the devices were under sufficient forward bias. It is also demonstrated that the device performance was improved by inserting an electron blocking $i-\mathrm{Mg}_{1-x} \mathrm{Zn}_{x} \mathrm{O}(0<x<1)$ layer.

Titkov, Delimova et al. [143] demonstrated white electroluminescence (EL) from $\mathrm{ZnO} / \mathrm{GaN}$ structures fabricated by pulsed laser deposition of ZnO:In onto MOCVD-grown GaN:Mg/GaN structures on $\mathrm{Al}_{2} \mathrm{O}_{3}$ substrates. The white EL was produced by superposition of two strongest emission lines, a narrow blue line at $440 \mathrm{~nm}$ and a broad yellow band around $550 \mathrm{~nm}$, which was attributed to the high density of structural defects at the $\mathrm{n}-\mathrm{ZnO} / \mathrm{p}-\mathrm{GaN}$ interface.

Bayram et al. [144] reported a hybrid green light-emitting diode comprised of $n-\mathrm{ZnO} /(\mathrm{InGaN} / \mathrm{GaN})$ multi-quantum-wells/p-GaN, which was grown on semi-insulating AlN/sapphire using pulsed laser deposition for the $n-\mathrm{ZnO}$ and metal organic chemical vapor deposition for the other layers. LEDs showed a turn-on voltage of $2.5 \mathrm{~V}$ and a room temperature EL centered at $510 \mathrm{~nm}$.

Besides the development of various device structures, the surface passivation was also used to improve the performance of the devices. For example, Yu-Lin Wang et al. [145] investigated the passivation effects of PECVD-deposited $\mathrm{SiO}_{2}$ and $\mathrm{SiN}_{\mathrm{x}}$ on $\mathrm{ZnO}$-based heterojunction $p$ - $i$ - $n$ LEDs.

In recent years, $p-\mathrm{ZnO}$ has also been used to construct hetrostructure LEDs in combination with other materials. However, many of the devices yield deep-level related emissions with none or small UV emissions. Mandalapu et al. [146] reported the Sb-doped $p-\mathrm{ZnO} / n$-Si heterojunction diode fabricated by MBE. Near-band edge and deep-level emissions were observed from the LED devices at both low temperatures and room temperature, which is due to band-to-band and band-to-deep level radiative recombination in $\mathrm{ZnO}$, respectively.

Different devices of complex structure have been reported. Kim et al. [147] fabricated ZnO-based LEDs using $\mathrm{ZnO}: \mathrm{P} / \mathrm{Zn}_{0.9} \mathrm{Mg}_{0.1} \mathrm{O} / \mathrm{ZnO} / \mathrm{Zn}_{0.9} \mathrm{Mg}_{0.1} \mathrm{O} / \mathrm{ZnO}: \mathrm{Ga} p-i-n$ heterostructures, which showed EL coming from deep level emission at low forward bias and near band edge ultraviolet emission at high bias. Ryu et al. [45] fabricated $\mathrm{ZnO}$-based ultraviolet LEDs comprised of a $\mathrm{ZnO} / \mathrm{BeZnO} \mathrm{MQW}$ active layer between $n$-type and $p$-type $\mathrm{ZnO}$ and $\mathrm{Be}_{0.3} \mathrm{Zn}_{0.7} \mathrm{O}$ layers. Arsenic and gallium were used as dopants for $p$-type and $n$-type layers. The EL emission was attributed to the active layer. This kind of device structure was also used for laser diode [148]. The lasing mechanism is inelastic exciton-exciton collision. Chu et al. [149] also reported $\mathrm{ZnO}$ based quantum well diode lasers, where Sb-doped $p$-type $\mathrm{ZnO} / \mathrm{Ga}$-doped $n$-type $\mathrm{ZnO}$ with an $\mathrm{MgZnO} / \mathrm{ZnO} / \mathrm{MgZnO}$ quantum well embedded in the junction was grown on Si by molecular beam epitaxy. The diodes emit lasing at room temperature with a very low threshold injection current density of $10 \mathrm{~A} / \mathrm{cm}^{2}$. The lasing mechanism is exciton-related recombination.

In addition, $\mathrm{ZnO}$ based LEDs and laser diodes of MIS or MOS structure were also demonstrated, for example, a MIS structure LED [150], and the electrically pumped UV random lasing in the $c$-axis oriented $\mathrm{ZnO}$-based $\mathrm{MOS}\left(\mathrm{Au} / \mathrm{SiO}_{x}(x<2) / \mathrm{ZnO}\right)$ device [151].

Finally, it should be of interest to mention the progress in nanostructured ZnO LEDs. Yang et al. [152] demonstrated efficient $\mathrm{UV}$ and red $\mathrm{EL}$ at room temperature from $\mathrm{ZnO}$ nanorod array light-emitting diodes, where the $p$-type $\mathrm{ZnO}$ was formed by $\mathrm{As}^{+}$ion implantation into the as-grown $\mathrm{ZnO}$ nanorods. Jeong et al. [153] reported $\mathrm{ZnO}$ nanowire-array-embedded $n-\mathrm{ZnO} / p$-GaN heterojunction light-emitting diodes, showing electroluminescence emission of the wavelength of 386 
$\mathrm{nm}$ come out from $\mathrm{ZnO}$ nanowire. Bao et al. [154] constructed a single nanowire light-emitting diode. A hybrid light-emitting $p$ - $n$ junction diode has been produced using $\mathrm{ZnO}$ nanorods as the $n$-type material [155]. Zimmler et al. [156] recently fabricated $\mathrm{ZnO}$ nanowire LEDs on a heavily doped $p$-type silicon substrate (Figure 19). The electroluminescence of the single wire LED was attributed to bound- and free-exciton related recombination, together with their LO phonon replicas.

Figure 19. Schematics of the $n-\mathrm{ZnO} / p$-Si nanowire LEDs. a. Top view, b. cross-sectional view. Reprinted from Ref. [156] with permission.

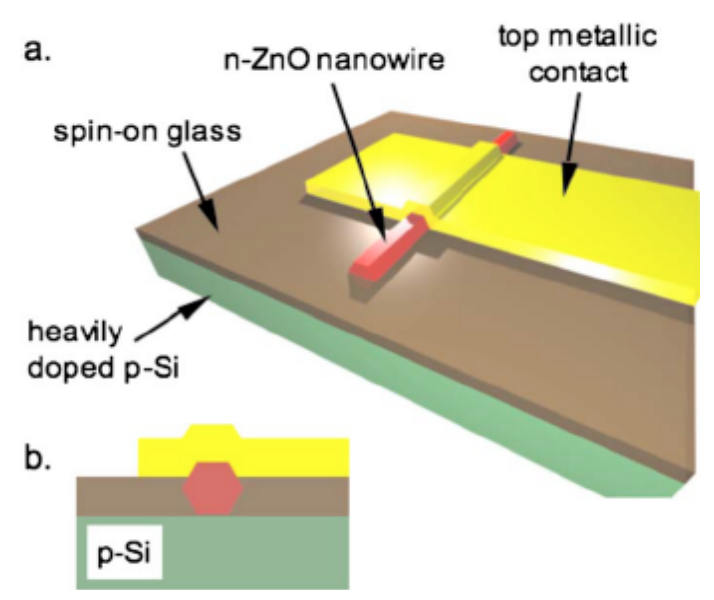

The random lasing action was also demonstrated by Leong and $\mathrm{Yu}[157]$ in $p$-SiC $(4 \mathrm{H}) / i-\mathrm{ZnO}-\mathrm{SiO}_{2}$ nanocomposite/ $n-\mathrm{ZnO}$ :Al heterojunction $(p-i-n)$ laser diodes. The intrinsic layer, inserted between the $n$ - and $p$-injection layers, consisted of $\mathrm{ZnO}$ powder embedded in $\mathrm{SiO}_{2}$ matrix, prepared by the sol-gel technique. The lasing was due to the $\mathrm{ZnO}$ clusters.

It is noted from the above discussion that defects in $\mathrm{ZnO}$, including undoped, manifest itself frequently in the luminescence. In order to fabricate $\mathrm{ZnO}$ based UV LED, $\mathrm{ZnO}$ of very few deep level defects has to be used for device fabrication. We have discussed above that the vapor cooling condensation method can deposit $\mathrm{ZnO}$ layer with much less oxygen vacancies. Using the method to deposit both doped and undoped $\mathrm{ZnO}$ layers, we have developed two kinds of $n-\mathrm{ZnO}$ based hybrid LEDs: the $p$-GaN/n-ZnO:In $(p-n)$ and $p$-GaN/i-ZnO/n-ZnO:In $(p-i-n)$ heterojunction light-emitting diodes [39]. The structures of both types of diodes are shown schematically in Figure 20.

The room temperature current-voltage characteristics clearly demonstrated a rectifying diodelike behavior for both devices. The EL spectra of the fabricated $p-n$ and $p-i-n$ devices under forward bias are shown in Figure 21 The EL spectrum of $p$-GaN/n-ZnO:In heterojunction LED consists of a broad emission band at $432 \mathrm{~nm}$, which is attributed to the transition from the conduction band to the acceptor level in the $\mathrm{Mg}$ doped $p$-GaN when electrons are injected from the $n$-ZnO:In into the Mg-doped $p$-GaN. It is interesting that the EL spectrum of $p-i-n$ device showed a pure UV band at $385 \mathrm{~nm}$, which is consistent with the PL spectrum of the $\mathrm{ZnO}$ layer deposited with the vapor cooling condensation method. It indicates that the EL emission of the $p-i-n$ LEDs comes from ZnO layer of the heterostructure, the undoped $i$ - $\mathrm{ZnO}$ layer inserted between $n-\mathrm{ZnO}: \mathrm{In}$ and $p$-GaN. It is due to the fact that the holes from $p$-GaN and electrons from $n$-ZnO:In are injected into the $i$ - $\mathrm{ZnO}$ layer and radiatively recombined there. It is clear that the UV EL of thus developed $p-i-n$ heterostructure is closely related to the fact that the inserted $i$ - ZnO layer, deposited by the vapor cooling condensation 
method, has much less luminescent defects. It is also worth while to point out that the developed $p-i-n$ LED is of potential applications in UV LEDs for high-temperature operation. [39]

Figure 20. Schematic of hybrid (a). $p-n$ and (b). $p-i-n$ heterojunction LEDs. Reprinted from Ref. [39] with permission.
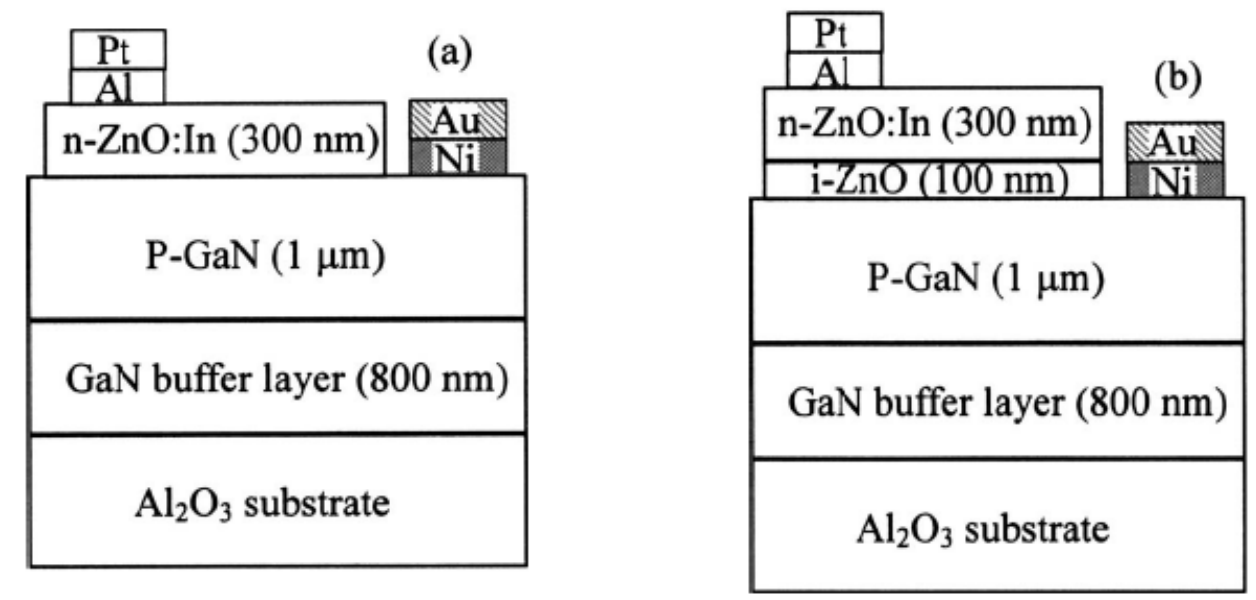

Figure 21. The room-temperature EL spectra of the $p$ - $n$ and $p-i-n$. Reprinted from Ref. [39] with permission.

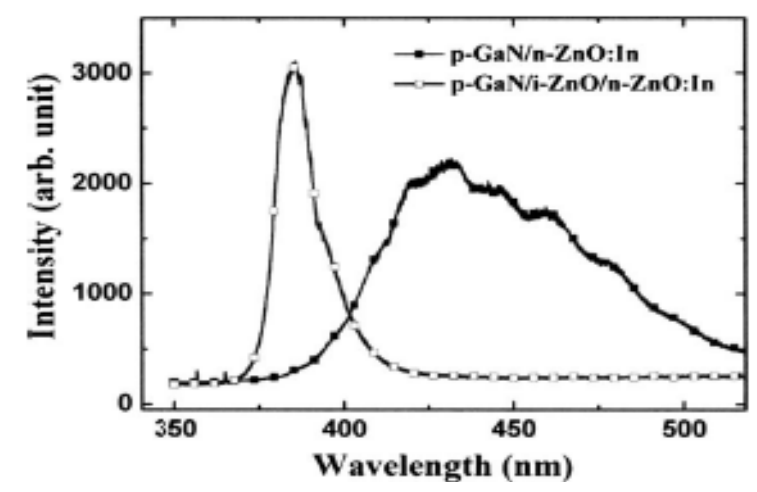

In a recent investigation, we succeeded in fabricating purely $\mathrm{ZnO}$ based $p-i-n$ UV LEDs [158]. Figure 22 shows the schematic diagram of the fabricated $p$-ZnO:AlN/i-ZnO/n-ZnO:In LED. The AlN codoped $\mathrm{p}-\mathrm{ZnO}$ layer was deposited on sapphire substrates by using the radio frequency (RF) magnetron co-sputtering system with a dual RF power supply. The $i$-ZnO and $n$-type ZnO:In films were fabricated by the vapor cooling condensation method. The resultant LEDs showed a UV EL peaked at $\sim 3.2 \mathrm{eV}$, operated under different injection currents at room temperature as shown in Figure 23. The observed EL band was also attributed to the radiative recombination in the $i$-ZnO layer where the deep-level defects were very few as demonstrated previously. 
Figure 22. Schematic of the light-emitting diodes $p$-ZnO:AlN/i-ZnO/n-ZnO:In. Reprinted from Ref. [158] with permission.

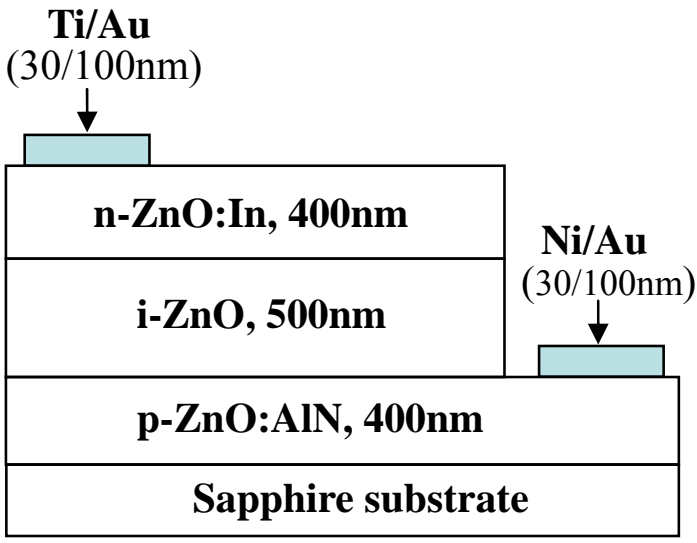

Figure 23. Room-temperature electroluminescence (EL) spectra of the $p-i-n \mathrm{ZnO}$-based LEDs under different operation currents. Reprinted from Ref. [158] with permission.

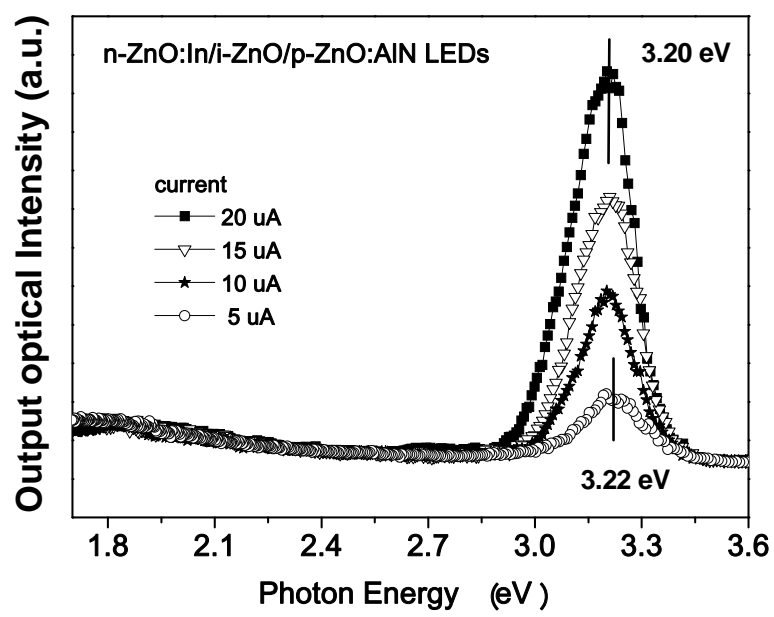

We also succeeded in fabricating $\mathrm{ZnO}$ nanorod-based heterostructured ultraviolet LEDs [159]. Figure 24 shows the schematic of the built $p-\mathrm{GaN}$ layer $/ i-\mathrm{ZnO}$ nanorod array $/ n-\mathrm{ZnO}: \mathrm{In}$ nanorod array heterostructured LEDs. Both $i$ - $\mathrm{ZnO}$ and $n$-ZnO:In nanorod arrays in the structure were grown on a $p$-GaN layer through an anodic alumina membrane (AAM) template using the vapor cooling condensation method.

Figure 25 shows the room temperature EL spectra of the $\mathrm{ZnO}$ nanorod based $p-i-n$ heterostructured LEDs operated at $15 \mu \mathrm{A}$ and $35 \mu \mathrm{A}$. In particular, the $p-i-n$ devices exhibit a UV EL emission centering at $386 \mathrm{~nm}$, which becomes dominant emission at higher injection current of $35 \mu \mathrm{A}$. This UV band is attributed to the near-band-edge emission of the $i$ - $\mathrm{ZnO}$ nanorod array of the $p-i-n$ structure. 
Figure 24. Schematic of $p-\mathrm{GaN}$ layer $/ i-\mathrm{ZnO}$ nanorod array $/ n-\mathrm{ZnO}: \mathrm{In}$ nanorod array heterostructured LEDs.

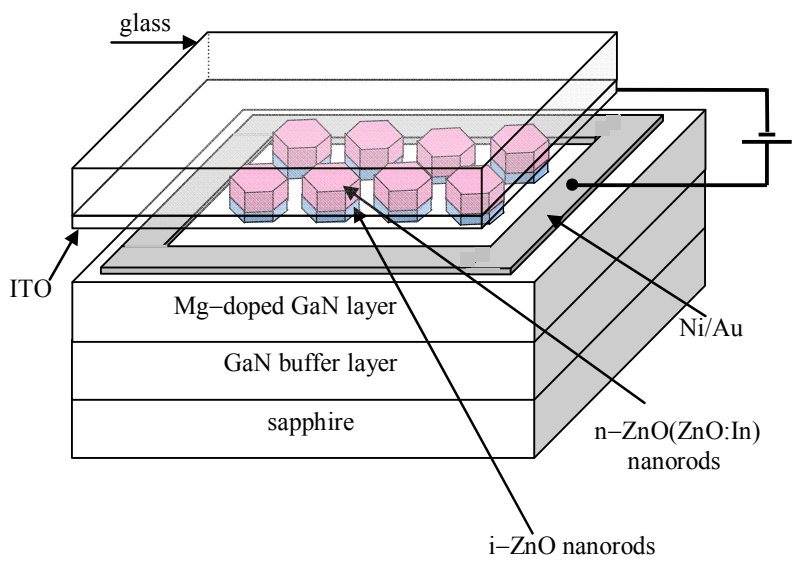

Figure 25. Room temperature EL spectra of the $\mathrm{ZnO}$ nanorod based heterostructured $p-i-n$ light-emitting diodes.

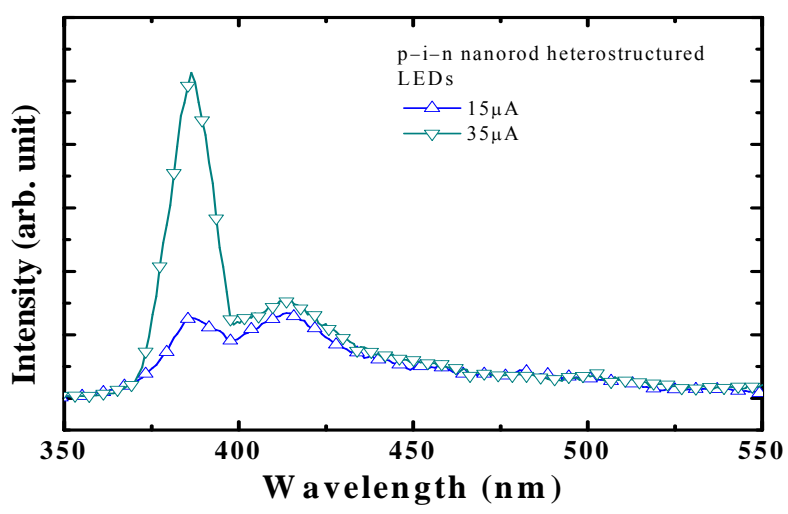

Nanostructure can also been used to improve the light extraction efficiency. In a recent work of our laboratory [160], Al-doped $\mathrm{ZnO}$ (AZO) films with Al nano clusters embedded were deposited by magnetron co-sputtering system, serving as the transparent conductive layer (to replace ITO film) of GaN-based light-emitting diodes, as shown schematically in Figure 26. 
Figure 26. Structures of LEDs with the periphery of bonding pad disconnected with the AZO film. Reprinted from Ref. [160] with permission.

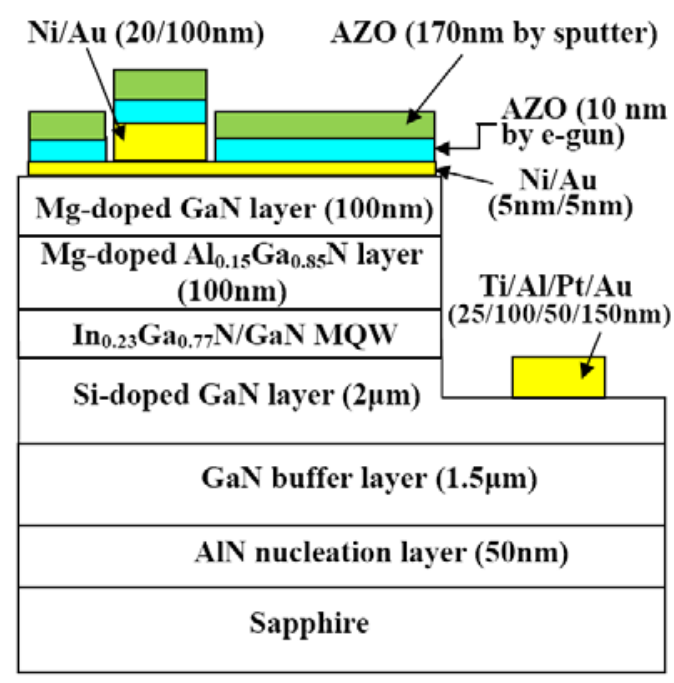

The fabricated LEDs with AZO film prepared at a higher DC Al co-sputtering power $(10 \mathrm{~W})$ show an increase of $20 \%$ in the light output power compared to the conventional LEDs, which is $10 \%$ more than that of LEDs with AZO prepared at Al co-sputtering power of $7 \mathrm{~W}$. The extra increase in the light output power was attributed to the formation of Al nanoclusters in AZO under higher Al sputtering power, which scattered the emitted light outward and hence increased the light extraction (Figure 27).

Figure 27. Light output power-current characteristics of LEDs with and without AZO films deposited under various Al dc power. Reprinted from Ref. [160] with permission.



\section{Summary}

$\mathrm{ZnO}$ related materials have been attracting intensive investigation due to inherent advantages and potential applications. In this paper, the recent progress on some aspects of the active research field, related to applications for the light-emitting diodes, has been reviewed in combination with the works carried out in our lab. One can feel that great progress has continuously been achieved, but there is still a long way to go for realizing extensive practical applications. Further efforts should be continued in various aspects of investigation for reaching the final goal. 


\section{Acknowledgment}

This work was supported from the National Science Council, Taiwan.

\section{References}

1. Özgür, Ü.; Alivov, Ya. I.; Liu, C.; Teke, A.; Reshchikov, M.A.; Doğan, S.; Avrutin, V.; Cho, S.-J.; Morkoçd, H. A comprehensive review of $\mathrm{ZnO}$ materials and devices. J. Appl. Phys. 2005, 98, 041301.

2. Klingshirn, C. ZnO: From basics towards applications. Phys. Stat. Sol. B 2007, 244, 3027-3073.

3. Ohshima, E.; Ogino, H.; Niikura, I.; Maeda, K.; Sato, M.; Ito, M.; Fukuda, T. Growth of the 2-in-size bulk ZnO single crystals by the hydrothermal method. J. Cryst. Growth 2004, 260, $166-170$.

4. Sekiguchi, T.; Miyashita, S.; Obara, K.; Shishido, T.; Sakagami, N. Hydrothermal growth of $\mathrm{ZnO}$ single crystals and their optical characterization. J. Cryst. Growth 2000, 214-215, 72-76.

5. Sakagami, N.; Yamashita, M.; Sekiguchi, T.; Miyashita, S.; Obara, K.; Shishido, T. Variation of electrical properties on growth sectors of $\mathrm{ZnO}$ single crystals. J. Cryst. Growth 2001, 229, 98-103.

6, Li, W.J.; Shi, E.W.; Zhong, W.Z.; Yin, Z.W. Growth mechanism and growth habit of oxide crystals. J. Cryst. Growth 1999, 203, 186-196.

7. Shiloh, M.; Gutman, J. Growth of $\mathrm{ZnO}$ single crystals by chemical vapour transport. J. Cryst. Growth 1971, 11, 105-109.

8. Matsumoto, K.; Noda, K. Crystal growth of $\mathrm{ZnO}$ by chemical transport using $\mathrm{HgCl} 2$ as a transport agent. J. Cryst. Growth 1990, 102, 137-140.

9. Look, D.C.; Reynolds, D.C.; Sizelove, J.R.; Jones, R.L.; Litton, C.W.; Cantwell, G.; Harsch, W.C. Electrical properties of bulk ZnO. Solid State Commun. 1998, 105, 399-401.

10. Nause, J.; Nemeth, B. Pressurized melt growth of ZnO boules. Semicond. Sci. Technol. 2005, 20, $\mathrm{S} 45-\mathrm{S} 48$.

11. Schulz, D.; Ganschow, S.; Klimm, D.; Neubert, M.; Rossberg, M.; Schmidbauer, M.; Fornari, R. Bridgman-grown zinc oxide single crystals. J. Crystal Growth 2006, 296, 27-30.

12. Lee, C.T.; Su, Y.K.; Wang, H.M. Effect of r.f. sputtering parameters on $\mathrm{ZnO}$ films deposited onto GaAs substrates. Thin Solid Films 1987, 150, 283-289.

13. Lee, C.T.; Su, Y.K.; Chen, S.L. Dependence of $\mathrm{ZnO}$ films on sputtering parameters and SAW device on ZnO/InP. J. Cryst. Growth 1989, 96, 785-789.

14. Gardeniers, J.G.E.; Rittersma, Z.M.; Burger, G.J. Preferred orientation and piezoelectricity in sputtered ZnO films. J. Appl. Phys. 1998, 83, 7844-7854.

15. Jeong, S.; Kim, B.; Lee, B. Photoluminescence dependence of $\mathrm{ZnO}$ films grown on $\mathrm{Si}(100)$ by radio-frequency magnetron sputtering on the growth ambient. Appl. Phys. Lett. 2003, 82, 2625-2627.

16. Kim, K.K., Song, J.H.; Jung, H.J.; Choi, W.K.; Park, S.J.; Song, J.H. The grain size effects on the photoluminescence of $\mathrm{ZnO} / \alpha-\mathrm{Al}_{2} \mathrm{O}_{3}$ grown by radio-frequency magnetron sputtering. J. Appl. Phys. 2000, 87, 3573-3575. 
17. Chen, P.L.; Ma, X.Y.; Yang, D.R. Ultraviolet electroluminescence from ZnO/p-Si heterojunctions. J. Appl. Phys. 2007, 101, 053103.

18. Liu, D.S.; Tsai, F.C.; Lee, C.T.; Sheu, C.W. Properties of zinc oxide films cosputtered with aluminum at room temperature. Jpn. J. Appl. Phys. 2008, 47, 3056-3062.

19. Lai, L.W.; Lee, C.T. Investigation of optical and electrical properties of $\mathrm{ZnO}$ thin films. Mater. Chem. Phys. 2008, 110, 393-396.

20. Liu, D.S.; Sheu, C.S.; Lee, C.T. Aluminum-nitride codoped zinc oxide films prepared using a radio-frequency magnetron cosputtering system. J. Appl. Phys. 2007, 102, 033516.

21. Vispute, R.D.; Talyansky, V.; Choopun, S.; Sharma, R.P.; Venkatesan, T.; He, M.; Tang, X.; Halpern, J.B.; Spencer, M.G.; Li, Y.X.; Salamanca-Riba, L.G.; Iliadis, A.A.; Jones, K.A. Heteroepitaxy of $\mathrm{ZnO}$ on $\mathrm{GaN}$ and its implications for fabrication of hybrid optoelectronic devices. Appl. Phys. Lett. 1998, 73, 348-350.

22. Bhosle, V.; Prater, J.T.; Yang, F.; Burk, D.; Forrest, S.R.; Narayan, J. Gallium-doped zinc oxide films as transparent electrodes for organic solar cell applications. J. Appl. Phys. 2007, 102, 023501 .

23. Fons, P.; Iwata, K.; Niki, S.; Yamada, A.; Matsubara, K. Growth of high-quality epitaxial ZnO films on $\alpha-\mathrm{Al}_{2} \mathrm{O}_{3}$. J. Cryst. Growth 1999, 201/202, 627-632.

24. Chen, Y.; Bagnall, D.M.; Koh, H.J.; Park, KT.; Hiraga, K.; Zhu, Z.Q.; Yao, T. Plasma assisted molecular beam epitaxy of $\mathrm{ZnO}$ on c -plane sapphire: Growth and characterization. J. Appl. Phys. 1998, 84, 3912-3918.

25. Mamdalapu, L.J.; Xiu, F.X.; Yang, Z.; Liu, J.L. Al/Ti contacts to Sb-doped p-type ZnO. J. Appl. Phys. 2007, 102, 023716.

26. Zhu, H.; Shan, C.X.; Li, B.H.; Zhang, J.Y.; Yao, B.; Zhang, Z.Z.; Zhao, D.X.; Shen, D.Z.; Fan, X.W. Ultraviolet electroluminescence from $\mathrm{MgZnO}$-based heterojunction light-emitting diodes. J. Phys. Chem. C 2009, 113, 2980-2982.

27. Sun, J.C.; Liang, H.W.; Zhao, J.Z.; Bian, J.M.; Feng, Q.J.; Hu, L.Z.; Zhang, H.Q.; Liang, X.P.; Luo, Y.M.; Du, G.T. Ultraviolet electroluminescence from n-ZnO:Ga/p-ZnO:N homojunction device on sapphire substrate with p-type $\mathrm{ZnO}: \mathrm{N}$ layer formed by annealing in $\mathrm{N}_{2} \mathrm{O}$ plasma ambient. Chem. Phys. Lett. 2008, 460, 548-551.

28. Liu, Y.; Gorla, C.R.; Liang, S.; Emanetoglu, N.; Lu, Y.; Shen, H. Wraback, M. Ultraviolet detectors based on epitaxial $\mathrm{ZnO}$ films grown by MOCVD. J. Electron. Mater. 2000, 29, 69-74.

29. Du, G.; Cui, Y.G.; Xia, X.C.; Li, X.P.; Zhu, H.C.; Zhang, B.L.; Zhang, Y.T.; Ma, Y. Visual-infrared electroluminescence emission from $\mathrm{ZnO} / \mathrm{GaAs}$ heterojunctions grown by metal-organic chemical vapor deposition. Appl. Phys. Lett. 2007, 90, 243504.

30. Li, X.P.; Zhang, B.L.; Dong, X.; Zhang, Y.T.; Xia, X.C.; Zhao, W.; Du, G.T. Room temperature electroluminescence from $\mathrm{ZnO} / \mathrm{Si}$ heterojunction devices grown by metal-organic chemical vapor deposition. J. Lumin. 2009, 129, 86-89.

31. Zhang, Y.; Lee, C.T. Site-controlled growth and field emission properties of $\mathrm{ZnO}$ nanorod arrays. J. Phys. Chem. C 2009, 113, 5920-5923.

32. Lee, S.D.; Kim, Y.S.; Yi, M.S.; Choi, J.Y.; Kim, S.W. Morphology control and electroluminescence of $\mathrm{ZnO}$ nanorod/GaN heterojunctions prepared using aqueous solution. $J$. Phys. Chem. C 2009, 113, 8954-8958. 
33. Bian, J.M.; Liu, W.F.; Sun, J.C.; Liang, H.W. Synthesis and defect-related emission of ZnO based light emitting device with homo- and heterostructure. J. Mater. Process. Technol. 2007, $184,451-454$.

34. Yuldashev, S.U.; Nusretov, R.A.; Khvan, I.V.; Yalishev, V.S.; Kang, T.W. White light emission from $\mathrm{ZnO} / \mathrm{Zn}_{0: 9} \mathrm{Mg}_{0: 1} \mathrm{O}$ heterostructures grown on Si substrates. Jpn. J. Appl. Phys. 2008, 47, $133-135$.

35. Dutta, M; Basak, D. p-ZnO/n-Si heterojunction: Sol-gel fabrication, photoresponse properties, and transport mechanism. Appl. Phys. Lett. 2008, 92, 212112.

36. Bhole, M.P.; Patil, D.S. Deposition of non-polar a-axis nanocrystalline $\mathrm{ZnO}$ thin films for light emitting applications. Optoelectron. Adv. Mater.-Rapid commun. 2007, 1, 672.

37. Lin, Y.J.; Wu, P.H.; Tsai, C.L.; Liu, C.J.; Lin, Z.R.; Chang, H.C.; Lee, C.T. Effects of Mg incorporation on the optical properties of $\mathrm{ZnO}$ prepared by the sol-gel method. J. Appl. Phys. 2008, 103, 113709.

38. Lin, Y.J.; Wu, P.H.; Tsai, C.L.; Liu, C.J.; Lee, C.T.; Chang, H.C.; Lin, Z.R.; Jeng, K.Y. Mechanisms of enhancing band-edge luminescence of $\mathrm{Zn}_{1-\mathrm{x}} \mathrm{Mg}_{\mathrm{x}} \mathrm{O}$ prepared by the sol-gel method. J. Phys. D Appl. Phys. 2008, 41, 125103.

39. Chuang, R.W.; Wu, R.X.; Lai, L.W.; Lee, C.T. ZnO-on-GaN heterojunction light-emitting diode grown by vapor cooling condensation technique. Appl. Phys. Lett. 2007, 91, 231113.

40. Liu, D.S.; Wu, C.C.; Lee, C.T. A transparent and conductive film prepared by RF magnetron cosputtering system at room temperature. Jpn. J. App. Phys. 2005, 44, 5119-5121.

41. Ohtomo, A.; Kawasaki, M.; Koida, T.; Masubuchi, K.; Koinuma, H.; Sakurai, Y.; Yoshida, Y.; Yasuda, T.; Segawa, Y. $\mathrm{Mg}_{\mathrm{x}} \mathrm{Zn}_{1-\mathrm{x}} \mathrm{O}$ as a II-VI widegap semiconductor alloy. Appl. Phys. Lett. 1998, 72, 2466-2468.

42. Gruber, T.; Kirchner, C.; Kling, R.; Reuss, F.; Waag, A. ZnMgO epilayers and ZnO-ZnMgO quantum wells for optoelectronic applications in the blue and UV spectral region. Appl. Phys. Lett. 2004, 84, 5359- 5361.

43. Shan, F.K.; Kim, B.I.; Liu, G.X.; Liu, Z.F.; Sohn, J.Y.; Lee, W.J.; Shin, B.C.; Yu, Y.S. Blueshift of near band edge emission in $\mathrm{Mg}$ doped $\mathrm{ZnO}$ thin films and aging. J. Appl. Phys. 2004, 95, 4772-4776.

44. Ryu, Y.R.; Lee, T.S.; Lubguban, J.A.; Corman, A.B.; White, H.W.; Leem, J.H.; Han, M.S.; Park, Y.S.; Youn, C.J.; Kim, W.J. Wide-band gap oxide alloy: BeZnO. Appl. Phys. Lett. 2006, 88, 052103.

45. Ryu, Y.; Lee, T.S.; Lubguban, J.A.; White, H.W.; Kim, B.J.; Park, Y.S.; Youn, C.J. Next generation of oxide photonic devices: ZnO-based ultraviolet light emitting diodes. Appl. Phys. Lett. 2006, 88, 241108.

46. Ma, D.W.; Ye, Z.Z.; Chen, L.L. Dependence of structural and optical properties of $\mathrm{Zn}_{1-\mathrm{x}} \mathrm{Cd}_{\mathrm{x}} \mathrm{O}$ films on the Cd composition. Phys. Stat. Sol. A 2004, 201, 2929-2933.

47. Gruber, T.; Kirchner, C.; Kling, R.; Reuss, F.; Waag, A.; Bertram, F.; Forster, D.; Christen, J.; Schreck, M. Optical and structural analysis of $\mathrm{ZnCdO}$ layers grown by metalorganic vapor-phase epitaxy. Appl. Phys. Lett. 2003, 83, 3290-3292.

48. Dingle, R. Luminescent transitions associated with divalent copper impurities and the green emission from semiconducting Zinc Oxide. Phys. Rev. Lett. 1969, 23, 579-581. 
49. Vanheusde, K.; Seager, C.H.; Warren, W.L.; Tallant, D.R.; Voigt, J.A. Correlation between photoluminescence and oxygen vacancies in $\mathrm{ZnO}$ phosphors. Appl. Phys. Lett. 1996, 68, 403-405.

50. Vanheusden, K.; Warren, W.L.; Seager, C.H.; Tallant, D.R.; Voigt, J.A.; Gnade, B.E. Mechanisms behind green photoluminescence in $\mathrm{ZnO}$ phosphor powders. J. Appl. Phys. 1996, 79, 7983-7990.

51. Kang, H.S.; Kang, J.S.; Kim, J.W.; Lee, S.Y. Annealing effect on the property of ultraviolet and green emissions of $\mathrm{ZnO}$ thin films. J. Appl. Phys. 2003, 95, 1246-1250.

52. Shan, F.K.; Liu, G.X.; Lee, W.J.; Shin, B.C. The role of oxygen vacancies in epitaxial-deposited ZnO thin films. J. Appl. Phys. 2007, 101, 053106.

53. Reynolds, D.C.; Look, D.C.; Jogai, B. Fine structure on the green band in ZnO. J. Appl. Phys. 2001, 89, 6189-6191.

54. Heo, Y.W.; Norton, D.P.; Pearton, S.J. Origin of green luminescence in $\mathrm{ZnO}$ thin film grown by molecular-beam epitaxy. J. Appl. Phys. 2005, 98, 073502.

55. Leiter, F.H.; Alves, H.R.; Hofstaetter, A.; Hofmann, D.M.; Meyer, B.K. The oxygen vacancy as the origin of a green emission in undoped ZnO. Phys. Sta. Sol. B 2001, 226, R4-R5.

56. Leiter, F.; Alves, H.; Pfisterer, D.; Romanov, N.G.; Hofmann, D.M.; Meyer, B.K. Oxygen vacancies in ZnO. Physica B 2003, 340-342, 201-204.

57. Hofmann, D.M.; Pfisterer, D.; Sann, J.; Meyer, B.K.; Tena-Zaera, R.; Munoz-Sanjose, V.T.; Pensl, Frank G. Properties of the oxygen vacancy in ZnO. Appl. Phys. A 2007, 88, 147-151.

58. Lai, L.W.; Yan, J.T.; Chen, C.H.; Lou, L.R.; Lee, C.T. Nitrogen function of aluminum-nitride codoped $\mathrm{ZnO}$ films deposited using cosputter system. J. Mater. Res. 2009, 24, 2252-2258.

59. Lin, P.F.; Ko, C.Y.; Lin, W.T.; Lee, C.T. Effects of processing parameters on ultraviolet emission of In-doped ZnO nanodisks grown by carbothermal reduction. Mater. Lett. 2007, 61, 1767-1770.

60. Kappers, L.A.; Gilliam, O.R.; Evans, S.M.; Halliburton, L.E.; Giles, N.C. EPR and optical study of oxygen and zinc vacancies in electron-irradiated ZnO. Nucl. Instr. Meth. Phys. Res. B 2008, 266, 2953-2957.

61. Vlasenko, L.S.; Watkins, G.D. Optical detection of electron paramagnetic resonance in room-temperature electron-irradiated ZnO. Phys. Rev. B 2005, 71, 125210.

62. Oba, F.; Togo, A.; Tanaka, I.; Paier, J.; Kresse, G. Defect energetics in ZnO: A hybrid Hartree-Fock density functional study. Phys. Rev. B 2008, 77, 245202.

63. Korsunska, N.O.; Borkovska, L.V.; Bulakh, B.M.; Khomenkova, L.Yu.; Kushnirenko, V.I.; Markevich, I.V. The influence of defect drift in external electric field on green luminescence of ZnO single crystals. J. Lumin. 2003, 102-103, 733-736.

64. Lin, B.X.; Fu, Z.X.; Jia, Y.B. Green luminescent center in undoped zinc oxide films deposited on silicon substrates. Appl. Phys. Lett. 2001, 79, 943-945.

65. Hur, T.B.; Jeen, G.S.; Hwang, Y.H.; Kim, H.Y. Photoluminescence of polycrystalline ZnO under different annealing conditions. J. Appl. Phys. 2003, 94, 5787-5790.

66. Reshchikov, M.A.; Morkoc, H.; Nemeth, B.; Nause, J.; Xie, J.; Hertog, B.; Osinsky, A. Luminescence properties of defects in ZnO. Physica B 2007, 401-402, 358-361.

67. Reshchikov, M.A.; Garbus, J.; Lopez, G.; Ruchala, M.; Nemeth, B.; Nause, J. Acceptors in ZnO studied by photoluminescence. Res. Soc. Proc. 2007, 957, K07-K19. 
68. Kohan, A.F.; Ceder, G.; Morgan, D.; Van de Walle, C.G. First-principles study of native point defects in ZnO. Phys. Rev. B 2000, 61, 15019-15027.

69. Janotti, A.; Van de Walle, C.G. Oxygen vacancies in ZnO. Appl. Phys. Lett. 2005, 87, 122102.

70. Patterson, C.H. Role of defects in ferromagnetism in $\mathrm{Zn}_{1-x} \mathrm{Co}_{x} \mathrm{O}$ : A hybrid density-functional study. Phys. Rev. B 2006, 74, 144432.

71. Hu, J.; Pan, B.C. Electronic structures of defects in $\mathrm{ZnO}$ : Hybrid density functional studies. $J$. Chem. Phys. 2008, 129, 154706.

72. Janotti, A.; Van de Walle, C.G. Native point defects in ZnO. Phys. Rev. B 2007, 76, 165202.

73. Tomlins, G.W.; Routbort, J.L.; Mason, T.O. Zinc self-diffusion, electrical properties, and defect structure of undoped single crystal zinc oxide. J. Appl. Phys. 2000, 87, 117-123.

74. Kröger, F.A. The Chemistry of Imperfect Crystals; North-Holland Pub. Co. American Elsevier: Amsterdam, NY, USA, 1973.

75. Lany, S.; Zunger, A. Dopability, intrinsic conductivity, and nonstoichiometry of transparent conducting oxides. Phys. Rev. Lett. 2007, 98, 045501.

76. Van de Walle, C.G.; Neugebauer, J. First-principles calculations for defects and impurities: Applications to III-nitrides. J. Appl. Phys. 2004, 95, 3851-3879.

77. Look, D.C.; Hemsky, J.W.; Sizelove, J.R. Residual native shallow donor in ZnO. Phys. Rev. Lett. 1999, 82, 2552-2555.

78. Lander, J.J. Concentration of hydrogen and semi-conductivity in $\mathrm{ZnO}$ under hydrogen-ion bombardment. J. Phys. Chem. Solids 1957, 3, 87-94.

79. Janotti, A.; Van de Walle, C.G. Hydrogen multicentre bonds. Nat. Mater.2007, 6, 44-47.

80. Lany, S.; Zunger, A. Anion vacancies as a source of persistent photoconductivity in II-VI and chalcopyrite semiconductors. Phys. Rev. B 2005, 72, 035215.

81. Smith, J.M.; Vehse, W.E. ESR of electron irradiated $\mathrm{ZnO}$ confirmation of the $\mathrm{F}^{+}$center. Phys. Lett. A 1970, 31,147-148.

82. Soriano, V.; Galland, D. Photosensitivity of the EPR spectrum of the $\mathrm{F}^{+}$center in ZnO. Phys. Status Solidi B 1976, 77, 739-743.

83. Zhang, Y.Z.; Lu, J.G.; Ye, Z.Z.; He, H.P.; Zhu, L.P.; Zhao, B.H.; Wan, L. Effects of growth temperature on $\mathrm{Li}-\mathrm{N}$ dual-doped $\mathrm{p}$-type $\mathrm{ZnO}$ thin films prepared by pulsed laser deposition. Appl. Surf. Sci. 2008, 254, 1993-1996.

84. Lu, J.G.; Zhang, Y.Z.; Ye, Z.Z.; Zeng, Y.J.; He, H.P.; Zhu, L.P.; Huang, J.Y.; Wang, L.; Yuan, J.; Zhao, B.H.; Li, X.H. Control of $p$ - and $n$-type conductivities in Li-doped $\mathrm{ZnO}$ thin films. Appl. Phys. Lett. 2006, 89, 112113.

85. Zeng, Y.J.; Ye, Z.Z.; Xu, W.Z.; Li, D.Y.; Lu, J.G.; Zhu, L.P.; Zhao, B.H. Dopant source choice for formation of $p$-type $\mathrm{ZnO}$ : Li acceptor. Appl. Phys. Lett. 2006, 88, 062107.

86. Wu, J.; Yang, Y.T. Deposition of K-doped p type $\mathrm{ZnO}$ thin films on (0001) $\mathrm{Al}_{2} \mathrm{O}_{3}$ substrates. Mater. Lett. 2008, 62, 1899-1901.

87. Wu, J.; Yang, Y.T. Fabrication and characterization of $\mathrm{K}-\mathrm{H}$ co-doped $\mathrm{p}-\mathrm{ZnO}$ thin films. $J$. Comput. Theor. Nanosci. 2008, 5, 1743-1745.

88. Kim, J.B.; Byun, D.; Ie, S.Y.; Park, D.H.; Choi, W.K.; Choi, J.W.; Angadi, B. Cu-doped ZnO-based p-n hetero-junction light emitting diode. Semicond. Sci. Technol. 2008, 23, 095004. 
89. Deng, R.; Zou, Y.M.; Tang, H.G. Correlation between electrical, optical properties and Ag2+ centers of ZnO:Ag thin films. Physica B 2008, 403, 2004-2007.

90. Kang, H.S.; Ahn, B.D.; Kim, J.H.; Kim, G.H.; Lim, S.H.; Chang, H.W.; Lee, S.Y. Structural, electrical, and optical properties of $p$-type $\mathrm{ZnO}$ thin films with Ag dopant. Appl. Phys. Lett. 2006, 88, 202108.

91. Duan, L.; Lin, B.X.; Zhang, W.Y.; Zhong, S.; Fu, Z.X. Enhancement of ultraviolet emissions from $\mathrm{ZnO}$ films by Ag doping. Appl. Phys. Lett. 2006, 88, 232110.

92. Park, C.H.; Zhang, S.B.; Wei, S.H. Origin of $p$-type doping difficulty in ZnO: The impurity perspective. Phys. Rev. B 2002, 66, 073202.

93. Bhuvana, K.P.; Elanchezhiyan, J.; Gopalakrishnan, N.; Balasubramanian, T. Codoped (AlN) and monodoped (Al) $\mathrm{ZnO}$ thin films grown by RF sputtering: A comparative study. Appl. Surf. Sci. 2008, 255, 2026-2029.

94. Kim, J.K.; Lim, J.W.; Kim, H.T.; Kim, S.H.; Yun, S.J. Fabrication of p-type ZnO thin films using rf-magnetron sputter deposition. Electrochem. Solid-State Lett. 2009, 12, H109-H112.

95. Lorenz, M.; Cao, B.Q.; Zimmermann, G.; Biehne, G.; Czekalla, C.; Frenzel, H.; Brandt, M.; von Wenckstern, H.; Grundmann, M. Stable p-type ZnO:P nanowire/n-type ZnO:Ga film junctions reproducibly grown by two-step pulsed laser deposition. J. Vac. Sci. Technol. B 2009, 27, 1693-1697.

96. Hu, G.X.; Gong, H. Unexpected influence of substrate temperature on the properties of P-doped ZnO. Acta Mater. 2008, 56, 5066-5070.

97. Look, D.C.; Renlund, G.M.; Burgener II, R.H.; Sizelove, J.R. As-doped p-type ZnO produced by an evaporation/sputtering process. Appl. Phys. Lett. 2004, 85, 5269-5271.

98. Wang, S.P.; Shan, C.X.; Li, B.H.; Zhang, J.Y.; Yao, B.; Shen, D.Z.; Fan, X.W. A facile route to arsenic-doped p-type ZnO films. J. Cryst. Growth 2009, 311, 3577-3580.

99. Zhang, J.Y.; Li, P.J.; Sun, H.; Shen, X.; Deng, T.S.; Zhu, K.T. Zhang, Q.F.; Wu, J.L. Ultraviolet electroluminescence from controlled arsenic-doped $\mathrm{ZnO}$ nanowire homojunctions. Appl. Phys. Lett. 2008, 93, 021116.

100. Xiu, F.X.; Yang, Z.; Mandalapu, L.J.; Zhao, D.T.; Liu, J.L. Photoluminescence study of Sb-doped $p$-type ZnO films by molecular-beam epitaxy. Appl. Phys. Lett. 2005, 87, 252102.

101. Chu, S.; Lim, J.H.; Mandalapu, L.J.; Yang, Z.; Li, L.; Liu, J.L. Sb-doped p-ZnO/Ga-doped n-ZnO homojunction ultraviolet light emitting diodes. Appl. Phys. Lett. 2008, 92, 152103.

102. Li, B.S.; Liu, Y.C.; Zhi, Z.Z.; Shen, D.Z.; Lu, Y.M.; Zhang, J.Y.; Fan, X.W.; Mu, R.X.; Henderson, D.O. Optical properties and electrical characterization of p-type $\mathrm{ZnO}$ thin films prepared by thermally oxiding $\mathrm{Zn}_{3} \mathrm{~N}_{2}$ thin films. J. Mater. Res. 2003, 18, 8-13.

103. Du, G.T.; Ma, Y.; Zhang, Y.T.; Yang, T.P. Preparation of intrinsic and N-doped p-type ZnO thin films by metalorganic vapor phase epitaxy. Appl. Phys. Lett. 2005, 87, 213103.

104. Xiao, Z.Y.; Liu, Y.C.; Zhang, J.Y.; Zhao, D.X.; Lu, Y.M.; Shen, D.Z.; Fan, X.W. Electrical and structural properties of p-type $\mathrm{ZnO}: \mathrm{N}$ thin films prepared by plasma enhanced chemical vapour deposition. Semicond. Sci. Technol. 2005, 20, 796-800.

105. Zhao, J.L.; Li, X.M.; Bian, J.M.; Yu, W.D.; Zhang, C.Y. Growth of nitrogen-doped p-type ZnO films by spray pyrolysis and their electrical and optical properties. J. Cryst. Growth 2005, 280, 495-501. 
106. Lu, J.G.; Zhang, Y.Z.; Ye, Z.Z.; Zhu, L.P.; Wang, L.; Zhao, B.H.; Liang, Q.L. Low-resistivity, stable $p$-type $\mathrm{ZnO}$ thin films realized using a Li-N dual-acceptor doping method. Appl. Phys. Lett. 2006, 88, 222114.

107. Lin, C.C.; Chen, S.Y.; Cheng, S.Y.; Lee, H.Y. Properties of nitrogen-implanted p-type ZnO films grown on $\mathrm{Si}_{3} \mathrm{~N}_{4} / \mathrm{Si}$ by radio-frequency magnetron sputtering. Appl. Phys. Lett. 2004, 84, 5040-5042.

108. Nakano, Y.; Morikawa, T.; Ohwaki, T.; Taga, Y. Electrical characterization of $p$-type N-doped $\mathrm{ZnO}$ films prepared by thermal oxidation of sputtered $\mathrm{Zn}_{3} \mathrm{~N}_{2}$ films. Appl. Phys. Lett. 2006, 88, 172103.

109. Wang, C.; Ji, Z.G.; Liu, K.; Xiang, Y.; Ye, Z.Z. p-Type ZnO thin films prepared by oxidation of $\mathrm{Zn}_{3} \mathrm{~N}_{2}$ thin films deposited by DC magnetron sputtering. J. Cryst. Growth 2003, 259, 279-281.

110. Tu, M.L.; Su, Y.K.; Ma, C.Y. Nitrogen-doped $p$-type $\mathrm{ZnO}$ films prepared from nitrogen gas radiofrequency magnetron sputtering. J. Appl. Phys. 2006, 100, 053705.

111. Yamamoto, T.; Katayama-Yoshida, H. Solution using a codoping method to unipolarity for the fabrication of p-type ZnO. Jpn. J. Appl. Phys. 1999, 38, L166-169.

112. Singh, A.V.; Mehra, R.M.; Wakahara, A.; Yoshida, A. p-Type conduction in codoped ZnO thin films. J. Appl. Phys. 2003, 93, 396-399.

113. Bian, J.M.; Li, X.M.; Gao, X.D.; Yu, W.D.; Chen, L.D. Deposition and electrical properties of $\mathrm{N}-$ In codoped p-type ZnO films by ultrasonic spray pyrolysis. Appl. Phys. Lett. 2004, 84, 541-543.

114. Zhuge, F.; Ye, Z.Z.; Zhu, L.P.; Lü, J.G.; Zhao, B.H.; Huang, J.Y.; Zhang, Z.H.; Wang, L.; Ji, Z.G. Electrical and optical properties of Al-N co-doped p-type zinc oxide films. J. Cryst. Growth 2004, 268, 163-168.

115. Lu, J.G.; Zhu, L.P.; Ye, Z.Z.; Zhuge, F.; Zhao, B.H.; Huang, J.Y.; Wang, L.; Yuan, J. p-type $\mathrm{ZnO}$ films by codoping of nitrogen and aluminum and $\mathrm{ZnO}$-based $\mathrm{p}-\mathrm{n}$ homojunctions. $J$. Cryst. Growth 2005, 283, 413-417.

116. Bhuvana, K.P.; Elanchezhiyan, J.; Gopalakrishnana, N.; Shinb, B.C.; Balasubramaniana, T. Realization of p-type conduction in $(\mathrm{ZnO})_{1-\mathrm{x}}(\mathrm{AlN})_{\mathrm{x}}$ thin films grown by RF magnetron sputtering. J. Alloys Compd. 2009, 478, 54-58.

117. Wang, H.; Ho, H.P.; Lo, K.C.; Cheah, K.W. Preparation of p-type ZnO films with (N,Ga) Co-doping by MOVPE. Mater. Chem. Phys. 2008, 107, 244-147

118. Sun, H.; Zhang, Q.; Zhang, J.; Deng, T.; Wu, J. Electroluminescence from ZnO nanowires with a p-ZnO film/n-ZnO nanowire homojunction. Appl. Phys. B 2008, 90, 543-546.

119. Cao, Y.G.; Miao, L.; Tanemura, S.; Tanemura, M.; Kuno, Y.; Hayashi, Y. Low resistivity p-ZnO films fabricated by sol-gel spin coating. Appl. Phys. Lett. 2006, 88, 251116.

120. Lai, L.W.; Yan, J.T.; Chen, C.H.; Lou, L.R.; Lee, C.T. Nitrogen function of aluminum-nitride codoped ZnO films deposited using cosputter system. J. Mater. Res. 2009, 24, 2252-2258.

121. Schmidt-Mende, L; MacManus-Driscoll, J.L. ZnO-nanostructures, defects, and devices. Mater. Today 2007, 10, 40-48.

122. Lee, W.; Jeong, M.C.; Myoung, J.M. Fabrication and application potential of $\mathrm{ZnO}$ nanowires grown on $\mathrm{GaAs}(002)$ substrates by metal-organic chemical vapour deposition. Nanotechnology 2004, 15, 254. 
123. Yuan, G.D.; Zhang, W.J.; Jie, J.S.; Fan, X.; Zapien, J.A.; Leung,Y.H.; Luo, L.B.; Wang, P.F.; Lee, C.S.; Lee, S.T. p-Type ZnO nanowire arrays. Nano Lett. 2008, 8, 2591-2597.

124. Wu. J.J.; Liu, S.C. Low-temperature growth of well-aligned $\mathrm{ZnO}$ nanorods by chemical vapor deposition. Adv. Mater. 2002, 14, 215-218.

125. Tak, Y.; Park, D.; Yong, K. Characterization of $\mathrm{ZnO}$ nanorod arrays fabricated on Si wafers using a low-temperature synthesis method. J. Vac. Sci. Technol. B 2006, 24, 2047-2052.

126. Zhang, Y.; Chen, D.J.; Lee, C.T. Free exciton emission and dephasing in individual $\mathrm{ZnO}$ nanowires. Appl. Phys. Lett. 2007, 91, 161911.

127. Lu, C.Y.; Chang, S.J.; Chang, S.P.; Lee, C.T.; Kuo, C.F.; Chang, H.M. Ultraviolet photodetectors with $\mathrm{ZnO}$ nanowires prepared on $\mathrm{ZnO}: \mathrm{Ga} /$ glass templates. Appl. Phys. Lett. 2006, $89,153101$.

128. Fonoberov, V.A.; Balandin, A.A. Origin of ultraviolet photoluminescence in $\mathrm{ZnO}$ quantum dots: Confined excitons versus surface-bound impurity exciton complexes. Appl. Phys. Lett. 2004, 85, 5971-5973.

129. Perebeinos, V.; Tersoff, J.; Avouris, Ph. Effect of exciton-phonon coupling in the calculated optical absorption of carbon nanotubes. Phys. Rev. Lett. 2005, 94, 027402.

130. Press, D.; Gotzinger, S.; Reitzenstein, S.; Hofmann, C.; Loffler, A.; Kamp, M.; Forchel, A.; Yamamoto, Y. Photon antibunching from a single quantum-dot-microcavity system in the strong coupling regime. Phys. Rev. Lett. 2007, 98, 117402.

131. Devos, A.; Poinsotte, F.; Groenen, J.; Dehaese, O.; Bertru, N.; Ponchet, A. Strong generation of coherent acoustic phonons in semiconductor quantum dots. Phys. Rev. Lett. 2007, 98, 207402.

132. Bahnemann, D.W.; Kormann, C.; Hoffmann, M.R. Preparation and characterization of quantum size zinc oxide: A detailed spectroscopic study. J. Phys. Chem.1987, 91, 3789-3798.

133. Han, X.H.; Wang, G.Z.; Wang, Q.T.; Cao, L.; Liu, R.B. Zou, B.G.; Hou, J.G. Ultraviolet lasing and time-resolved photoluminescence of well-aligned $\mathrm{ZnO}$ nanorod arrays. Appl. Phys. Lett. 2005, 86, 223106.

134. Choi, Y.S.; Kang, J.W.; Hwang, D.K.; Park, S.J. Recent advances in ZnO-based LEDs. IEEE Trans. Electron Dev. 2010, 57, 26-41.

135. Jiao, S.J.; Zhang, Z.Z.; Lu, Y.M.; Shen, D.Z.; Yao, B.J.; Zhang, Y.; Li, B.H.; Zhao, D.X.; Fan, X.W.; Tang, Z.K. ZnO $p$ - $n$ junction light-emitting diodes fabricated on sapphire substrates. Appl. Phys. Lett. 2006, 88, 031911.

136. Liu, W.; Gu, S.L.; Ye, J.D.; Zhu, S.M.; Liu, S.M.; Zhou, X.; Zhang, R.; Shi, Y.; Zheng, Y.D.; Hang, Y.; Zhang, C.L. Blue-yellow ZnO homostructural light-emitting diode realized by metalorganic chemical vapor deposition technique. Appl. Phys. Lett. 2006, 88, 092101.

137. Wei, Z.P.; Lu, Y.M.; Shen, D.Z.; Zhang, Z.Z.; Yao, B.; Li, B.H.; Zhang, J.Y.; Zhao, D.X.; Fan, X.W.; Tang, Z.K. Room temperature $p$ - $n$ ZnO blue-violet light-emitting diodes. Appl. Phys. Lett. 2007, 90, 042113.

138. Ye, Z.Z.; Lu, J.G.; Zhang, Y.Z.; Zeng, Y.J.; Chen, L.L.; Zhuge, F.; Yuan, G.D.; He, H.P.; Zhu, L.P.; Huang, J.Y.; Zhao, B. H. ZnO light-emitting diodes fabricated on Si substrates with homobuffer layers. Appl. Phys. Lett. 2007, 91, 113503. 
139. Du, G.T.; Liu, W.F.; Bian, J.M.; Hu, L.Z.; Liang, H.W.; Wang, X.S.; Liu A.M.; Yang, T.P. Room temperature defect related electroluminescence from $\mathrm{ZnO}$ homojunctions grown by ultrasonic spray pyrolysis. Appl. Phys. Lett. 2006, 89, 052113.

140. Yu, Q.X.; Xu, B.; Wu, Q.H.; Liao, Y.; Wang, G.Z.; Fang, R.C.; Lee, H.Y.; Lee, C.T. Optical properties of $\mathrm{ZnO} / \mathrm{GaN}$ heterostructure and its near-ultraviolet light-emitting diode. Appl. Phys. Lett. 2003, 83, 4713-4715.

141. Rogers, D.J.; Teherani, F.H.; Yasan, A.; Minder, K.; Kung, P.; Razeghi, M. Electroluminescence at $375 \mathrm{~nm}$ from a $\mathrm{ZnO} / \mathrm{GaN}: \mathrm{Mg} / \mathrm{c}-\mathrm{Al}_{2} \mathrm{O}_{3}$ heterojunction light emitting diode. Appl. Phys. Lett. 2006, 88, 141918.

142. Long, H.; Fang, G.; Huang, H.; Mo, X.; Xia, W.; Dong, B.; Meng, X.; Zhao, X. Ultraviolet electroluminescence from $\mathrm{ZnO} / \mathrm{NiO}-$ based heterojunction light-emitting diodes. Appl. Phys. Lett. 2009, 95, 013509.

143. Titkov, I.E.; Delimova, L.A.; Zubrilov, A.S.; Seredova, N.V.; Liniichuk, I.A.; Grekhov, I.V. $\mathrm{ZnO} / \mathrm{GaN}$ heterostructure for LED applications. J. Modern Optics 2009, 56, 653-660.

144. Bayram, C.; Teherani, F.H.; Rogers, D.J.; Razeghi1, M. A hybrid green light-emitting diode comprised of $n-\mathrm{ZnO} /(\mathrm{InGaN} / \mathrm{GaN})$ multi-quantum-wells/p-GaN. Appl. Phys. Lett. 2008, 93, 081111.

145. Wang, Y.L.; Kim, H.S.; Norton, D.P.; Pearton, S.J.; Ren, F. Dielectric passivation effects on ZnO light emitting diodes. Appl. Phys. Lett. 2008, 92, 112101.

146. Mandalapu, L.J.; Yang, Z.; Chu, S.; Liu, J.L. Ultraviolet emission from Sb-doped p-type ZnO based heterojunction light-emitting diodes. Appl. Phys. Lett. 2008, 92, 122101.

147. Kim, H.S.; Lugo, F.; Pearton, S.J.; Norton, D.P.; Wang, Y.L.; Ren, F. Phosphorus doped ZnO light emitting diodes fabricated via pulsed laser deposition. Appl. Phys. Lett. 2008, 92, 112108.

148. Ryu, Y.R.; Lubguban, J.A.; Lee, T.S.; White, H.W.; Jeong, T.S.; Youn, C. J.; Kim, B.J. Excitonic ultraviolet lasing in ZnO-based light emitting devices. Appl. Phys. Lett. 2007, 90, 131115.

149. Chu, S.; Olmedo, M.; Yang, Z.; Kong, J.Y.; Liu, J.L. Electrically pumped ultraviolet ZnO diode lasers on Si. Appl. Phys. Lett. 2008, 93, 181106.

150. Chen, P.L.; Ma, X.Y.; Yang D.R. Fairly pure ultraviolet electroluminescence from ZnO-based light-emitting devices. Appl. Phys. Lett. 2006, 89, 111112.

151. Ma, X.Y.; Chen, P.L.; Li, D.S.; Zhang, Y.Y.; Yang, D.R. Electrically pumped ZnO film ultraviolet random lasers on silicon substrate. Appl. Phys. Lett. 2007, 91, 251109.

152. Yang, Y.; Sun, X.W.; Tay, B.K.; You, G.F.; Tan, S.T.; Teo, K.L. A $p$ - $n$ homojunction ZnO nanorod light-emitting diode formed by As ion implantation. Appl. Phys. Lett. 2008, 93, 253107.

153. Jeong, M.C.; Oh, B.Y.; Ham, M.H.; Myounga, J.M. Electroluminescence from ZnO nanowires in $n-\mathrm{ZnO}$ film/ZnO nanowire array $/ p-\mathrm{GaN}$ film heterojunction light-emitting diodes. Appl. Phys. Lett. 2006, 88, 202105.

154. Bao, J.M.; Zimmler, M.A.; Capasso, F.; Wang, X.W.; Ren, Z.F. Broadband ZnO single-nanowire light-emitting diode. Nano Lett. 2006, 6, 1719-1722.

155. Kolnenkamp, R.; Word, R.C.; Godinez, M. Ultraviolet electroluminescence from ZnO/polymer heterojunction light-emitting diodes. Nano Lett. 2005, 5, 2005-2008. 
156. Zimmler, M.A.; Voss, T.; Ronning, C.; Capasso, F. Exciton-related electroluminescence from ZnO nanowire light-emitting diodes. Appl. Phys. Lett. 2009, 94, 241120.

157. Leong, E.S.P.; Yu, S.F. UV random lasing action in p-SiC(4H)/i-ZnO- $\mathrm{SiO}_{2}$ nanocomposite/n-ZnO:Al heterojunction diodes. Adv. Mater. 2006, 18, 1685-1688.

158. Lee, C.T.; Lin, Y.H.; Lai, L.W.; Lou, L.R. Mechanism investigation of p-i-n ZnO-based light-emitting diodes. IEEE Photo. Technol. Lett. 2010, 22, 30-32.

159. Yan, J.T.; Chen, C.H.; Yen, S.F.; Lee, C.T. Ultraviolet $\mathrm{ZnO}$ nanorod $/ p-\mathrm{GaN}$ heterostructured light-emitting diodes. IEEE Photo. Technol. Lett. 2010, 22, 146-148.

160. Lee, C.T.; Chou, Y. H.; Yan, J.T.; Lee, H.Y. Light enhancement of Al nanoclusters embedded in Al-doped $\mathrm{ZnO}$ films of GaN-based light-emitting diodes. J. Vac. Sci. Technol. B 2009, 27, 1901-1903.

(C) 2010 by the authors; licensee Molecular Diversity Preservation International, Basel, Switzerland. This article is an open-access article distributed under the terms and conditions of the Creative Commons Attribution license (http://creativecommons.org/licenses/by/3.0/). 